Review Article

\title{
Mesenchymal Stem Cell Therapy for Diabetic Kidney Disease: A Review of the Studies Using Syngeneic, Autologous, Allogeneic, and Xenogeneic Cells
}

\author{
Christian Sávio-Silva, ${ }^{1}$ Stephany Beyerstedt, ${ }^{1}$ Poliana E. Soinski-Sousa, ${ }^{1}$ Expedito B. Casaro, ${ }^{1}$ \\ Maria Theresa A. Balby-Rocha, ${ }^{1}$ Antônio Simplício-Filho, ${ }^{1}$ Jamille Alves-Silva, ${ }^{1}$ \\ and Érika B. Rangel (iD ${ }^{1,2}$
}

${ }^{1}$ Albert Einstein Research and Education Institute, Hospital Israelita Albert Einstein, São Paulo, SP, Brazil

${ }^{2}$ Nephrology Division, Federal University of São Paulo, São Paulo, SP, Brazil

Correspondence should be addressed to Érika B. Rangel; erikabr@uol.com.br

Received 11 June 2020; Revised 31 October 2020; Accepted 3 November 2020; Published 20 November 2020

Academic Editor: Mustapha Najimi

Copyright (c) 2020 Christian Sávio-Silva et al. This is an open access article distributed under the Creative Commons Attribution License, which permits unrestricted use, distribution, and reproduction in any medium, provided the original work is properly cited.

\begin{abstract}
Diabetic kidney disease (DKD) is a microvascular complication of diabetes mellitus (DM) and comprises multifactorial pathophysiologic mechanisms. Despite current treatment, around $30-40 \%$ of individuals with type 1 and type 2 DM (DM1 and DM2) have progressive DKD, which is the most common cause of end-stage chronic kidney disease worldwide. Mesenchymal stem cell- (MSC-) based therapy has important biological and therapeutic implications for curtailing DKD progression. As a chronic disease, DM may impair MSC microenvironment, but there is compelling evidence that MSC derived from DM1 individuals maintain their cardinal properties, such as potency, secretion of trophic factors, and modulation of immune cells, so that both autologous and allogeneic MSCs are safe and effective. Conversely, MSCs derived from DM2 individuals are usually dysfunctional, exhibiting higher rates of senescence and apoptosis and a decrease in clonogenicity, proliferation, and angiogenesis potential. Therefore, more studies in humans are needed to reach a conclusion if autologous MSCs from DM2 individuals are effective for treatment of DM-related complications. Importantly, the bench to bedside pathway has been constructed in the last decade for assessing the therapeutic potential of MSCs in the DM setting. Laboratory research set the basis for establishing further translation research including preclinical development and proof of concept in model systems. Phase I clinical trials have evaluated the safety profile of MSC-based therapy in humans, and phase II clinical trials (proof of concept in trial participants) still need to answer important questions for treating DKD, yet metabolic control has already been documented. Therefore, randomized and controlled trials considering the source, optimal cell number, and route of delivery in DM patients are further required to advance MSC-based therapy. Future directions include strategies to reduce MSC heterogeneity, standardized protocols for isolation and expansion of those cells, and the development of well-designed largescale trials to show significant efficacy during a long follow-up, mainly in individuals with DKD.
\end{abstract}

\section{Introduction}

1.1. Epidemiology. The global diabetes mellitus (DM) prevalence in 2019 was estimated at $9.3 \%$ (463 million) in adults aged $20-79$ years, rising to $10.2 \%$ (578 million) by 2030 and $10.9 \%$ (700 million) by 2045 [1]. The prevalence is higher in urban $(10.8 \%)$ than rural $(7.2 \%)$ areas, and in highincome $(10.4 \%)$ than low-income $(4.0 \%)$ countries. Of importance, one in two (50.1\%) people living with DM does not know that they have DM. Therefore, almost half a billion people are living with diabetes worldwide, and the number is projected to increase by $25 \%$ in 2030 and $51 \%$ in 2045 . Likewise, the global prevalence of impaired glucose tolerance is estimated to be $7.5 \%$ (374 million) in 2019 and projected to reach $8.0 \%$ (454 million) by 2030 and $8.6 \%$ (548 million) by $2045[1]$. 
Using the WHO (World Health Organization) database, the International Diabetes Federation documented that $8.4 \%$ of all-cause deaths were attributable to DM in adults aged 20-79 years, almost 5.1 million deaths [2]. A sensitivity analysis adjusting relative risks by $20 \%$ found that the estimate of DM-attributable mortality lies between $5.1 \%$ of total mortality (3.3 million deaths) and $10.1 \%$ of total mortality (6.6 million deaths) [2]. Overall, 1 in 12 global all-cause deaths was estimated to be attributable to DM in adults [2].

Diabetic kidney disease (DKD) is a microvascular complication of DM and the most common cause of end-stage kidney disease (ESKD) worldwide, with approximately $30 \%$ of patients with type $1 \mathrm{DM}$ (DM1) and approximately $40 \%$ of patients with type 2 DM (DM2) developing DKD, as reviewed elsewhere [3]. DKD accounts for cardiovascular complications and the high mortality rate of patients with DM. In the United States, the unadjusted prevalence of CKD stages 1-5 (not including ESKD) was estimated to be $14.8 \%$ (from 2011 through 2014), with stage 3 being the most prevalent stage [4]. There is an increase of $1.1 \%$ per year of new cases of ESKD, and the active waiting list is 2.8 times larger than the availability of donor kidneys.

1.2. Pathophysiology of DKD. Natural history of DKD comprises hyperfiltration, progressive albuminuria, decrease in eGFR (estimated glomerular filtration rate), and, ultimately, ESRD. Yet, albuminuria is a continuum; eGFR deterioration can start to decline before progression to overt nephropathy, which can be explained by other risk factors, such as obesity, hypertriglyceridaemia, hypertension, and glomerular hyperfiltration [5]. Thus, albuminuria and eGFR predict the progression of renal impairment in DM1 and DM2 individuals with DKD. Classification of DKD is summarized as follows: (i) stage 1 (prenephropathy): normoalbuminuria $(<30 \mathrm{~g} / \mathrm{g}$ $\mathrm{Cr}$ ) and eGFR $\geq 30 \mathrm{ml} / \mathrm{min} / 1.73 \mathrm{~m}^{2}$, (ii) stage 2 (incipient nephropathy): microalbuminuria (30-299 g/g Cr) and eGFR $\geq 30 \mathrm{ml} / \mathrm{min} / 1.73 \mathrm{~m}^{2}$, (iii) stage 3 (overt proteinuria): macroalbuminuria $(\geq 300 \mathrm{~g} / \mathrm{g} \mathrm{Cr}$ ) or persistent proteinuria $(\geq 0.5)$ and $\mathrm{eGFR} \geq 30 \mathrm{ml} / \mathrm{min} / 1.73 \mathrm{~m}^{2}$, (iv) stage 4 (kidney failure): any albuminuria status and eGFR $<30 \mathrm{ml} / \mathrm{min} / 1.73 \mathrm{~m}^{2}$, and (v) stage 5 (renal replacement therapy): any status on continued dialysis therapy [6].

Histologically, metabolic changes associated with DM lead to glomerular hypertrophy, glomerulosclerosis, arteriolar hyalinosis, arteriosclerosis, tubule-interstitial inflammation, and fibrosis. The main glomerular changes consist of thickening of the glomerular basement membrane (GBM), expansion of the mesangial matrix, atrophy and loss of podocyte pedicels associated with effacement, and diffuse or nodular intercapillary glomerulosclerosis (Kimmelstiel-Wilson lesion) [3].

Systemic inflammatory milieu due to metabolic dysregulation (hyperglycemia, hyperlipidaemia, insulin resistance, and $\beta$-cell dysfunction) and haemodynamic changes (systemic hypertension) characterizes DKD pathophysiology. In addition, DKD is associated with endothelial dysfunction; activation of RAAS (renin-angiotensin-aldosterone system); increase in AGEs (advanced glycation end products); elevation of NADPH oxidase; upregulation of GLUT1; generation of reactive oxygen species (ROS); upregulation of growth factors, such as VEGF (vascular endothelial growth factor) and TGF- $\beta$ (transforming growth factor- $\beta$ ); activation of aldose reductase and the polyol pathways; mitochondrial dysfunction; downregulation of adiponectin; and nitric oxide (NO) loss, as reviewed elsewhere $[7,8]$. Those derangements entail adverse effects on the renal system, such as oxidative stress; apoptosis; autophagy dysfunction; intracellular signaling cascade activation, such as protein kinase $\mathrm{C}$ (PKC)/mitogenassociated protein kinase (MAPK) and subsequent NF- $\kappa \mathrm{B}$; and inflammation, which is associated with inflammatory interleukins (IL), cytokines, and chemokines (IL-1, IL-6, IL18 , TNF- $\alpha$ (tumor necrosis factor- $\alpha$ ), CSF-1 (colony stimulating factor-1), MCP-1 (monocyte chemoattractant protein-1), and MIF (macrophage inflammatory factor)). Exacerbated production of profibrotic cytokines (CTGF (connective tissue growth factor) and TGF- $\beta$ ) associated with fibrosis is also involved in DKD. Collectively, all those mechanisms contribute to DKD progression and to both functional (declining eGFR and proteinuria) and structural (fibroblast accumulation, mesangial cell expansion and proliferation, extracellular matrix accumulation, GBM thickening, podocyte loss/dysfunction, tubule-interstitial dysfunction, and endothelial dysfunction) kidney damage, which lead ultimately to systemic complications (ESKD, cardiocerebrovascular events, vascular events, neuropathy, and death).

1.3. Treatment. Due to DM prevalence worldwide, it is crucial to develop cost-effective strategies at every step: (1) prevention of obesity, (2) screening for and prevention of diabetes in an at-risk population, (3) glycemic control once diabetes develops, (4) blood pressure (BP) control once hypertension develops, (5) screening for diabetic chronic kidney disease (CKD), (6) RAAS inhibition/blockade in those with diabetic $\mathrm{CKD}$, and (7) control of other cardiovascular (CV) risk factors such as management of low-density lipoprotein cholesterol (LDL-C) $[9,10]$.

Despite diabetic patients being treated with angiotensinreceptor-blockers (ARBs), renal disease progression risk over 2 years increases with increasing proteinuria and albuminuria and decreasing eGFR [11]. To note, RAAS inhibition possesses remarkable renoprotective effect when used in earlier stages of renal disease, whereas in late stages, that approach has less efficacy [12]. Yet, the combination of ARBs and angiotensin-converting-enzyme (ACE) inhibitors is a robust approach to block RAAS; it was associated with an increased risk of adverse events, such as acute kidney injury and hyperkalemia [13].

Novel drugs have been recently associated with clinical benefit profiles, which should be considered in the decisionmaking process when treating patients with DM2. Glucagon-like peptide 1 receptor agonists (GLP1-RA) and sodium-glucose cotransporter-2 inhibitors (SGLT2i) reduce atherosclerotic major adverse cardiovascular (CVs) events to a similar degree in patients with established atherosclerotic CV disease, whereas SGLT2i have a more marked effect on preventing hospitalization for heart failure and progression of DKD $[14,15]$. 
In the DKD treatment setting with drugs and lifestyle changes, novel approaches are further required to halt the progression of DKD or regenerate the damaged tissue, such as cell therapy [16]. In this review, we will focus on both in vitro and in vivo studies using syngeneic, autologous, allogeneic, or xenogeneic mesenchymal stem cells (MSCs) for treating DKD. We will describe the main findings of MSCbased therapy in preclinical and clinical studies and discuss the benefits, outcomes, and challenges of that therapy for halting DKD progression.

\section{Mesenchymal Stem Cells (MSCs)}

MSCs, commonly referred to as mesenchymal stem cells or mesenchymal stromal cells, are a diverse population of cells with a wide range of potential therapeutic applications for different organs and tissues. MSCs can be obtained from many tissue sources, consistent with their broad, possibly ubiquitous distribution.

Historically, MSCs were isolated from bone marrow (BM-MSC) and spleen from guinea pigs by Friedenstein et al. [17]. They observed that BM-MSCs were plastic adherent cells and were capable of forming single-cell colonies. When BM-MSCs are expanded in culture, round-shaped colonies resembling fibroblastic cells are formed and subsequently identified by a Colony Forming Unit-fibroblast (CFU-f) assay. They were the first to demonstrate that BMMSCs exhibited multipotential capacity to differentiate into mesoderm-derived tissues.

BM-MSCs can be isolated by (a) using gradient centrifugation (Ficoll or Percoll) to separate nonnucleated red blood cells from nucleated cells, (b) taking advantage of their ability to adhere to plastic, (c) taking advantage of the ability of monocytes to be separated from BM-MSCs by trypsinization [18].

During the 1980s, BM-MSCs were found to be able to differentiate into osteoblasts, chondrocytes, adipocytes, and muscle tissue [19]. In the 1990s, BM-MSCs were shown to differentiate into ectodermal-derived tissue $[20,21]$. During the early $21^{\text {st }}$ century, in vivo studies documented that human BM-MSCs differentiated into endodermal-derived cells [22, 23], cardiomyocytes [24], and renal mesangial and epithelial tubular cells $[25,26]$. However, their efficiency to differentiate into other tissues is extremely low in vivo and therefore is not the main mechanism of tissue repair and regeneration.

More recently, BM-MSC secretome has demonstrated potential clinical applications and includes both soluble proteins (cytokines, chemokines, growth factors, and proteases) and factors released in extracellular vesicles, for example, microvesicles (size 100-1000 nm) and exosomes (EXOs; size $40-100 \mathrm{~nm}$ ) [27]. These extracellular vesicles contain proteins, lipids, mRNA, and miRNA and rarely DNA [28]. Mitochondria or mitochondrial DNA can also be transferred by extracellular vesicles or nanotubes built between cells that are regulated by dynamin-related proteins Miro-1 and Miro-2 [29]. Therefore, BM-MSC secretome is involved in cell survival and growth, immune modulation, and attenuation of fibrosis. High-resolution proteomic and lipidomic analyses have shown that key regulators of some pathways are enriched in both microvesicles and EXOs, including
GTPase activity, translation, vesicle/membrane, and glycolysis, whereas other pathways are enriched more in microvesicles (cell motion, mitochondria, endoplasmic reticulum, and proteasome) and others in EXOs (extracellular matrix, binding, immune response, and cell adhesion) [30].

Of importance, MSCs possess ubiquitous distribution in perivascular niches and can be derived and propagated in vitro from different organs and tissues (AT, amniotic fluid, $\mathrm{BM}$, brain, cord blood, dental pulp, kidney, liver, lung, muscle, pancreas, placental membranes, spleen, thymus, and large vessels, such as aorta artery and vena cava) [31, 32]. Most frequent sources of MSC isolation include $\mathrm{BM}$, adipose tissue (AT-MSC), and umbilical cord blood (UCB-MSC). In $\mathrm{BM}$, one in 10,000 nucleated cells is a MSC. To note, $1.0 \mathrm{~g}$ of aspirated AT yields approximately $3.5 \times 10^{5}-1 \times 10^{6}$ ATMSCs. This is compared to $5 \times 10^{2}-5 \times 10^{4}$ of BM-MSCs isolated from $1.0 \mathrm{~g}$ of BM aspirate [33].

Isolation of MSCs from AT is based on mincing fat tissue, followed by several washings in order to remove contaminating hematopoietic cells, incubation of tissue fragments with collagenase, and centrifugation of the digest, thereby separating the floating population of mature adipocytes from the pelleted stromal vascular fraction [34]. UCB-MSC is also a straightforward protocol and consists in carefully dissecting the UC into two regions, e.g., the cord lining and Wharton's jelly. After cutting the UCB longitudinally, it is necessary to scrape Wharton's jelly away from the blood vessels and inner epithelium and then remove the blood vessels. After collecting any remaining perivascular Wharton's jelly tissue under and around the blood vessels, which represents the cord lining, the digestion of that tissue with trypsin will allow the adherence of tissue pieces and the egression of MSCs in 2-3 days, as briefly described elsewhere [35].

MSC populations originating from different tissues and organs exhibit similar morphology and, to a certain extent, surface marker profile [31]. On the other hand, differentiation assays indicate some variation among cultures in the frequency of cells that possess the capacity to differentiate into osteogenic or adipogenic lineages. For example, vena cava-derived MSCs were very efficient at depositing a mineralized matrix, whereas muscle-derived MSCs showed little efficiency for osteogenic differentiation, as opposed to an inverse capacity of adipocyte differentiation of these cells [31]. Conversely, adipogenic differentiation observed in lung-, brain-, and kidney-derived MSCs seemed to be less efficient. Likewise, UCB-MSCs exhibit significantly stronger osteogenic capacity but lower capacity for adipogenic differentiation in comparison to BM-MSCs [36]. Of importance, AT-MSCs exhibit similar capacity of differentiation when compared to BM-MSCs [37].

The International Society for Cell Therapy (ISCT) established the characteristics of MSCs from all sources, either autologous or allogeneic: (1) adherence to plastic under standard culture conditions; (2) expression of CD73, CD90, and CD105 surface molecules in the absence of CD34, CD45, HLA-DR, CD14 or CD11b, CD79, or CD19 surface molecules, as assessed by flow cytometry analysis; and (3) differentiation capacity for osteoblasts, adipocytes, and chondroblasts in vitro [38]. In comparison to fibroblasts, both cells express CD44 and CD49b, whereas CD20, CD31, 
CD33, CD117, and CD133 are negative in both cells. Some markers are only expressed in MSCs (CD10, CD26, CD54, CD106, CD146, and ITGA11), as well as the potential of colony forming [39].

A recent update from ISCT includes analyses that mitigate the heterogeneity of MSCs, such as assays that demonstrate the secretion of trophic factors, the modulation of immune cells, and other relevant functional properties, such as angiogenesis [40]. The ISCT MSC committee recommended that the studies should describe (i) tissue source origin of MSCs, which would highlight tissuespecific properties; (ii) the stemness properties described by both in vitro and in vivo data; and (iii) a robust matrix of functional assays to demonstrate the properties of these cells associated with the intended therapeutic mode of actions. In addition, basic assays for MSC-based products comprise donor screening, viability test, purity test (residual contaminant tests and pyrogenic/endotoxin tests), safety test (bacterial, fungal, mycoplasma, viral tests, and tumorigenicity assays), identity tests (immunophenotypic profiles), and potency tests (multilineage differentiation, secretion profiles, CFU-f assay, and immunosuppressive assay). All of these procedures should be done in a Good Manufacturing Practice (GMP) facility.

To assess MSC self-renewal capacity, doubling time and CFU-f are broadly used. In a particular DM setting, immunological assays can be based on activation protocols that discriminate between TLR- (Toll-like receptor-) 4dependent phenotype MSC-1 and TLR3-dependent MSC2 phenotype [41]. That polarization may be achieved with short-term incubation $(1 \mathrm{~h})$ with LPS $(10 \mathrm{ng} / \mathrm{ml})$ or poly(I:C) (poly-deoxy-inosinic-deoxy-cytidylic acid) $(1 \mathrm{mg} / \mathrm{ml})$, respectively, followed by incubation for 24 to $48 \mathrm{~h}$ in growth medium, since LPS acts as an agonist for TLR4 and poly(I:C) acts as an agonist for TLR3. Another approach for assessing MSC-based immunomodulatory properties would be based on the coculture of MSCs with cells of the immune system by the (a) stimulation of MSCs with IFN- $\gamma$ (IFN- $\gamma$ primed MSCs) and subsequent analysis of various ribonucleic acids (IDO, CXCL9, CXCL10, CXCL11, CIITA, HLAD, and PDL1 or CD274, ICAM-1 or CD54, TLR3, TRAIL, and CCL5) and (b) coculture of MSCs with human peripheral blood mononuclear cells (PBMCs) and analysis of the signature of the secretome in relation to cytokine/chemokine secretion and $\mathrm{T}$ cell proliferation [42]. Coculture of MSCs and B-lymphocytes and NK cells may also be a useful strategy to assess MSC-based immunomodulatory properties. To note, such assays are important in addressing MSCs before and after freezing. It is also worth mentioning that PBMCs should be used from donors that show a normal pattern of proliferation and without much variability.

\subsection{In Vitro Studies: Recapitulation of DKD} Microenvironment for Evaluating the Therapeutic Potential of MSCs. To recapitulate, the in vitro DKD milieu is challenging since cell-cell and cell-matrix interaction is severely affected during disease progression. The most frequent approach is to evaluate the cells under normal glucose medium $(5.5 \mathrm{mmol} / \mathrm{l})$ and high glucose $(25-30 \mathrm{mmol} / \mathrm{l}$ or less frequent $40 \mathrm{mmol} / \mathrm{l})$. Mannitol $(20 \mathrm{mmol} / \mathrm{l})$ associated with normal glucose $(5.5 \mathrm{mmol} / \mathrm{l})$ is used as a control of osmolality. Peroxide hydrogen and TNF- $\alpha$ may be added to the medium as inducers of oxidative stress [43] and inflammation [44], respectively. The coculture of MSCs, MSC-conditioned medium or EXOs, and different types of renal cells represents a platform in which the DKD microenvironment may be recapitulated. The most appropriate approach to recreate $\mathrm{DKD}$ in vitro (high glucose, peroxide hydrogen, and TNF- $\alpha$ ), the amount of cells (ratio of MSCs and renal cells), the type of cell interaction (direct versus indirect, e.g., using a Transwell ${ }^{\circledR}$ chamber), and duration of the coculture $(6 \mathrm{~h}, 12 \mathrm{~h}, 24 \mathrm{~h}, 48 \mathrm{~h}$, $72 \mathrm{~h}$, or $96 \mathrm{~h}$ ) were broadly tested in the literature.

Immortalized mouse podocytes cultured in high glucose medium and cocultured directly with BM-MSC transfected with miR124a, for $24 \mathrm{~h}$, exhibited increased viability and decreased apoptosis (decrease in caspase- 3 and Bax gene expression and increase in $\mathrm{Bcl} 2$ gene expression) [45]. Mouse podocytes (MPC5 cells) treated with high glucose medium and cocultured with AT-MSC-derived EXOs, for $24 \mathrm{~h}, 48 \mathrm{~h}$, $72 \mathrm{~h}$, and $96 \mathrm{~h}$, exhibited less apoptosis in concentrationand time-dependent manners [46]. Mechanistically, ATMSC-derived EXOs enhanced autophagy flux and reduced podocyte injury by inhibiting the activation of mTOR/SMAD1 signaling and increasing miR-486 expression.

For glomerular mesangial cells (GMCs) cultured in high glucose medium, direct coculture with BM-MSC (ratio 10:1) or MSC-conditioned medium for $72 \mathrm{~h}$ decreased equally TGF- $\beta$ and phosphorylated SMAD2/3 proteins, which were abrogated by BMP-7 antibody [47]. Likewise, GMC cultured in a high glucose medium and cocultured with BM-MSC $\left(4 \times 10^{5}\right.$ cells/well $)$ in a Transwell ${ }^{\circledR}$ chamber for $72 \mathrm{~h}$ led to an increase in lipoxin A4, a key lipid involved in inflammation resolution [48].

For renal tubular epithelial cells (TECs) cultured in high glucose medium, the coculture for $24 \mathrm{~h}$ with ATMSC $\left(1 \times 10^{5}\right.$ cells/well $)$ using a Transwell ${ }^{\circledR}$ chamber inhibited apoptosis of those cells, induced klotho expression, and downregulated the $\mathrm{Wnt} / \beta$-catenin signaling pathway [49]. In addition, high glucose medium supplemented with TNF- $\alpha$ may also mimic the DKD microenvironment [44]. In that study, proximal TECs (HK2) were cocultured with UCB-MSC in a Transwell ${ }^{\circledR}$ chamber at a $5: 1$ ratio, for $72 \mathrm{~h}$, in high glucose medium and TNF- $\alpha$. UCB-MSC increased cell viability, ATP production, and E-cadherin expression, as opposed to a decrease in fibronectin, SGLT2, pNF- $\kappa$ B p65, and MCP-1.

Not only MSCs but also EXOs cocultured for $96 \mathrm{~h}$ with TECs in primary renal cell culture of streptozotocin- (STZ) induced diabetic rats entailed in antiapoptotic and antidegenerative effects (increase in $\mathrm{ZO}-1$ and lectin expression and decrease in TGF- $\beta 1$ ) [50].

Endothelium may also be damaged during DM progression. Thus, the murine islet microvascular endothelium cell line experienced apoptosis and endothelial cell activation (increase in VCAM (vascular cell adhesion molecule) expression and reduction in eNOS (endothelial nitric oxide synthase) phosphorylation) upon $\mathrm{H}_{2} \mathrm{O}_{2}$ conditioning, which 
was abrogated by MSC treatment and activation of the $\beta$ catenin-dependent Wnt signaling pathway [51].

Therapeutic potential of MSCs can also be verified in a coculture platform with other cells that play a role in DKD progression, such as macrophages. Indirect coculture of BM-MSC $\left(3 \times 10^{4}\right.$ cells/well $)$ with LPS-treated macrophages (rat peritoneum; $1.5 \times 10^{5}$ cells/well), at a $1: 5$ ratio for $6 \mathrm{~h}$, led to a decrease in IL- $1 \beta$, IL- 6, MCP- 1 , and TNF- $\alpha$ expression [52]. Coculture of immortalized macrophage cell line (RAW264.7) with human UBC-MSCs (at a 2:1 ratio), for $24 \mathrm{~h}$, suppressed LPS-induced M1 macrophage polarization (decrease in inflammatory proteins, such as IL- $1 \beta$, TNF- $\alpha$, IL-6, and iNOS (inducible nitric oxide synthase)), which was mediated by the increase in arginase 1 production [53]. To note, iNOS metabolizes arginine to nitric oxide and citrulline, whereas arginase (M2-macrophage) hydrolyzes arginine to ornithine and urea. Therefore, the arginase pathway limits arginine availability for nitric oxide synthesis, and ornithine itself can further lead to polyamine and proline synthesis, which have important biological implications for proliferation and tissue repair. In addition, MSC-conditioned medium reversed cytokine-mediated mitochondrial dysfunction in HK2 cells (TECs) by increasing mitochondria mass and biogenesis and decreasing ROS production [53].

Aging has also an adverse impact on MSC function and possesses biological and therapeutic implications. Moreover, CKD and DM are linked to accelerated aging. The p66 protein is related to aging and controls cellular response to oxidative stress, senescence, and apoptosis. Renal-derived Sca$1^{+}$MSCs from p66 knockout mice and cultured in high glucose medium exhibited higher rates of proliferation; decreased senescent proteins (p53, p21, and p16 ${ }^{\mathrm{INK} 4 \mathrm{a}}$ ); higher levels of IGF-1 (insulin growth factor-1), HGF (hepatocyte growth factor), and VEGF; and upregulation of $\beta$ catenin signaling when compared to renal-derived $\mathrm{Sca}-1^{+}$ MSC from wild-type mice [54].

2.2. Preclinical Studies: Small and Large Animals. MSC-based therapy is a promising strategy for accelerating kidney recovery, repairing and regenerating tissue damage after acute injury following ischemia-reperfusion, kidney transplant, and drug-mediated toxicity, as reviewed elsewhere [55]. In a meta-analysis including MSC from rat and mice ( 200 animals treated) and different types of acute and chronic kidney injury (but not DKD), routes of delivery (intravenous, intrarenal, intraperitoneal, and intra-arterial), and MSC number (range, $7.5 \times 10^{4}-3.0 \times 10^{6}$ ), the beneficial outcomes for kidney recovery favored MSC treatment [56].

Of importance, MSC efficacy is challenged by several factors, such as viability, cell source, MSC phenotype, homing capacity, route of delivery, site of infusion, number of infusions, cell passage, cell potency, severity of condition, and target impact [57]. In the sensitivity analysis of that metaanalysis, there was a trend toward greater reduction in serum creatinine of the MSC-treated group when compared with the control group regarding the MSC number $(>106)$, arterial route (versus intravenous route), model of injury (ischemiareperfusion injury versus toxic and chronic injury), and late administration ( $>1$ day after injury) [56]. Thus, these data provided insightful information in terms of MSC efficacy and safety in preclinical models and paved the way for studies in other kidney diseases, such as DKD.

Next, we discuss some key aspects of MSC-based cell therapy in preclinical studies.

2.2.1. MSC Phenotype. Emerging concepts indicate that MSCs may function as sensors and switchers of inflammation, which may explain their immunomodulatory properties $[58,59]$. In an inflammatory environment associated with high levels of IFN- $\gamma$ (interferon- $\gamma$ ) and TNF- $\alpha$, MSCs acquire an immunosuppressive phenotype (MSC2) and through Toll-like receptor- (TLR-) 3 lead to an increase in production of TGF- $\beta$, IDO (indoleamine 2,3-dioxygenase), NO (nitric oxide), and PGE2 (prostaglandin E2). These events stimulate the amount of $\mathrm{CD} 4^{+} \mathrm{CD} 25^{+} \mathrm{FoxP}^{+}{ }^{+} \mathrm{T}$ regulatory cells. Conversely, in the absence of an inflammatory environment (low levels of IFN- $\gamma$ and TNF- $\alpha$ ), MSCs acquire a proinflammatory phenotype, and through TLR4, LPS (lipopolysaccharide), and high levels of chemokine C-X-C motif ligand (CXCL)9, CXCL10, MIP- (macrophage inflammatory protein-) $1 \alpha$, MIP- $1 \beta$, and CCL5/RANTES (regulated on activation, normal $\mathrm{T}$ cell expressed and secreted), but low levels of IDO, NO, and PGE2, activation of cytotoxic T lymphocytes is triggered.

Interaction of MSCs and monocytes play also a key role in our understanding of mechanisms of MSC-mediated tissue regeneration $[58,59]$. When MSCs acquire an immunosuppressive phenotype (high levels of IDO and PGE2) in the presence of IL-6, there is a polarization from monocytes (M0) to macrophage anti-inflammatory phenotype (M2 macrophages; CD206 and CD163 expression; production of high levels of IL-6 and IL-10). On the other hand, proinflammatory MSC-induced phenotype may lead to polarization from $\mathrm{M} 0$ to proinflammatory macrophage (M1 macrophage; CD86 expression; production of high levels of IFN- $\gamma$ and TNF- $\alpha$ ).

However, further investigation is warranted to verify whether MSC phenotype changes in accordance with DKD progression. In other settings, such as kidney transplant, MSC infusion posttransplant allowed their preferential recruitment in the inflammatory milieu of the graft created by ischemia/reperfusion injury, and once in that environment, MSC contributed to upregulation of inflammation, thereby causing premature graft dysfunction [60]. By contrast, autologous BM-derived MSC infusion induced a significant prolongation of kidney graft survival by a $\mathrm{T}$ cell regulatory-dependent mechanism when a protocol biopsy showed signs of subclinical rejection and/or an increase in interstitial fibrosis/tubular atrophy 4 weeks or 6 months posttransplantation [61]. Additionally, autologous BMderived MSC, when injected before living-related kidney transplant, led to a decrease in the circulating memory $\mathrm{CD}^{+} \mathrm{T}$ lymphocytes and donor-specific $\mathrm{CD} 8^{+} \mathrm{T}$ lymphocyte cytolytic response [62] and might induce tolerance [63].

2.2.2. Routes of MSC Delivery. Stem cell route delivery (intravenous, intra-arterial, or intraparenchymal) may affect MSC efficiency for kidney repair and regeneration in different 
models of acute and chronic kidney injury. The intravenous route is the route used most often, to inject not only MSCs [64-67] but also different kidney-derived progenitor/stem cells $[68,69]$ in several models of acute and chronic kidney injury in rodents. To note, MSCs, BM-derived mononuclear cells (BM-MNCs), and other kidney progenitors are initially trapped inside the pulmonary microvasculature following intravenous administration [70]. In line with these findings, the number of cells, multiple intravenous injections, and cell size increase the chance of pulmonary trapping, as murine MSCs measure 15-19 $\mu \mathrm{m}[70,71]$. Similar observations were reported in nonhuman primates when MSCs were injected intravenously $[72,73]$. Sodium nitroprusside pretreatment, a vasodilator, may reduce mouse MSC trapping in the lungs [71] and require further analyses of its efficiency in larger animals.

However, infused human MSCs are able to migrate beyond the lungs after intravenous administration in a rodent model of cisplatin-induced acute kidney injury and may be detected in peritubular areas, where they ameliorated renal cell apoptosis and increased cell proliferation [74].

Intra-arterial routes for delivering progenitor/stem cells include intracarotid [75], intracardiac [76], or intra-aorta [77-81]. When the intra-aorta route is employed, the clamps can be applied above and below the renal arteries $[77,78]$ or only below the renal arteries [79-81], which can be challenging in small animals [82]. Bioluminescence analyses supported a distinct localization of MSCs in the murine kidneys submitted to ischemia-reperfusion injury when these cells were injected in the suprarenal aorta (intracarotid), in contrast to intrajugular vein injection, which was associated with predominant accumulation of cells in both lungs [83]. In larger animals (ovine), autologous MSCs delivered through renal arteries were also effective in reducing tubular injury after ischemia-reperfusion injury [84].

Although intraparenchymal (under renal capsule) administration of progenitor/stem cells or MSCs has beneficial effect on kidney repair [79, 85-89], this route is less practical for clinical application, especially when the renal disease is diffuse and technical issues limit a broader use, such as haemorrhage. However, the bioengineering field has undergone considerable evolution, so that MSC sheets may be transplanted directly into the kidneys and suppress the progression of DKD in rats [90].

2.2.3. MSC Homing (CXCR4 and SDF-1 Axis). Stromalderived factor-1 (SDF-1), also known as CXCL12, and its receptor C-X-C chemokine receptor 4 (CXCR4) axis is a crucial key pathway in cell trafficking.

After acute kidney injury, the levels of SDF-1 mRNA levels increase more than 2.5 -fold and remain high as $\sim 2.0$ fold after $24 \mathrm{~h}$ within kidney cortex tissue [91]. That increase leads to homing and migration of CXCR4-expressing cells in the injured kidneys. However, MSCs, which express CXCR4, migrate to damaged tissues with limited efficiency. Therefore, CXCR4 gene-modified BM-MSCs lead to accumulation of these cells in the injured kidney and activation of PI3K/AKT and MAPK signaling pathway [92], which represents a promising strategy for advancing MSC-based therapy.
2.2.4. Animal Models of Diabetic Kidney Disease. There are several animal models of DKD in rodents, which mimics DM in humans either DM1 or DM2. Therefore, DM and subsequent $\mathrm{DKD}$ can be obtained by genetic manipulation, induced by drugs (streptozotocin or STZ) or high-fat diet, or even a combination of approaches, including uninephrectomy to accelerate DKD progression, as reviewed elsewhere [16].

Thus, pharmacologic induction of DKD with STZ, with or without accelerating factors, such as high-fat diet, uninephrectomy, or use of the nonobese diabetic (NOD) strain, has been the most common rodent model of DKD to study the potential therapy of MSCs [7].

The Animal Models of Diabetic Complications Consortium (AMDCC) defined the following criteria for validating a progressive mouse model of $\mathrm{DKD}$ [93]: (i) greater than $50 \%$ decline in GFR over the lifetime of the animal; (ii) greater than 10-fold increase in albuminuria compared to controls for the strain at the same age and gender; and (iii) kidney-specific histopathology induced by DM: advanced mesangial matrix expansion \pm nodular sclerosis and mesangiolysis, any degree of arteriolar hyalinosis, and GBM thickening by $>50 \%$ over baseline tubule-interstitial fibrosis.

Recent models of DM1 (E1-DKD; expression of a kinasenegative epidermal growth factor receptor in pancreatic islet cells e) and DM2 (BTBR ${ }^{o b / o b}$; knockout for leptin) that reflect human DKD $[94,95]$ may represent promising models to verify not only stem cell-based therapy but also drug, gene, nanoparticle, and other approaches to halt DKD progression [16]. E1-DKD and BTBR ${ }^{o b / o b}$ models develop proteinuria in a time-dependent manner, mesangial expansion, thickening of GBM, widening of podocyte foot process, podocyte apoptosis, glomerular sclerosis, and reduction of podocyte genes and protein. Notably, $\mathrm{BTBR}^{o b / o b}$ mice comprise a reversible model of DM upon leptin administration [96], which indicates, therefore, a robust model to test MSC therapeutic potential.

NOD mice develop autoimmune insulitis caused by polygenes including specific MHC class II alleles and many nonMHC loci, mimicking DM1 [97]. NOD mice develop albuminuria associated with enlarged glomeruli and mesangial sclerosis. An insulin-2 Akita mouse exhibits an autosomal dominant mutation in the Ins-2 gene that causes misfolding of insulin protein [97]. These mice develop increased mesangial matrix and GBM thickening, but no mesangiolysis or widespread marked or nodular mesangial sclerosis. Similarly, the $d b / d b$ mouse is a model of DM2, which develops hyperglycemia, obesity, and albuminuria due to a G-to-T mutation in the gene coding the leptin receptor $(d b / d b)$ [97]. They develop glomerular hypertrophy, mesangial matrix expansion, and GBM thickening, but no mesangiolysis or nodular mesangial sclerosis. The Otsuka Long-Evans Tokushima Fatty (OLETF) rat model of hyperphagia-induced obesity due to a spontaneous lack of $\mathrm{CCK}_{1}$ (cholecystokinin) receptors represents a broadly established model of DM2, which develops proliferation of the mesangial matrix, GBM thickening, diffuse glomerulosclerosis, nodular lesions, tubular atrophy associated with mononuclear cell infiltration, and fibrosis [97]. Other rodent models of DM2 and DKD include GK rat, NZO mouse, KK-Ay mouse, and ZDF rat, as reviewed elsewhere [97]. 
In Table 1, we document the preclinical studies, including the MSC source, number of cells and injections, route of delivery, and outcomes in the DKD setting [44, 45, 47, 48, $49,50,52,90,98-118]$. The majority of the studies comprised syngeneic MSCs obtained from BM, single-dose injection via an intravenous route, and successful outcomes for halting DKD progression.

Briefly, these studies provided evidences that MSC-based therapy may decrease fasting blood glucose (FBG) and glycated haemoglobin (HbA1c) in either DM1 or DM2 animals, and in DM1 animals, plasmatic insulin levels increased or exogenous insulin requirement decreased. Likewise, MSCbased therapy has important therapeutic implications in the DKD setting, providing insights into cellular and molecular mechanisms. Therefore, MSCs contributed to improving functional parameters, such as the increase in glomerular filtration and the decrease in albuminuria and structural parameters. The studies indicated an improvement in renal histology and the curtailing of biological processes of inflammation, cell death (apoptosis and necrosis), oxidative stress, and fibrosis. In addition, MSC-based therapy promoted preservation of renal mass, upregulation of tubular epithelial and podocyte genes, augmentation in growth factors within the kidneys, decreasing endothelium damage, amelioration of tubular glucotoxicity by decreasing cellular glucose uptake in the kidneys, and increasing the antiaging klotho protein.

Differentiated BM-MSCs to insulin-secreting $\beta$-cells may also represent a promising strategy to treat DM and clinical complications, as documented by the amelioration of endothelium activation by decreasing fibrinogen levels, blood pressure, cytoplasmic calcium, and apoptosis (p53 and Bax), as well as by improving cardiac parameters in STZinduced diabetic rats [119].

Likewise, secretome of BM-MSC obtained from Zucker DM2 fatty rats improved endothelial cell function by increasing $\sim 3$-fold the formation of tubule-like structures and migration of these cells, which was mediated by IGF-1, LTBP-1 (latent TGF- $\beta$ binding protein), and LTBP-2, as well as by promoting vascular formation in vivo [120]. In addition, diabetic secretome exhibited increased expression of proangiogenic genes (ANPEP, MCP-1, MIP-2, HIF-2, IGF1 , IL-6, PLAU, TIE1, and TNF- $\alpha$ ) and reduced antiangiogenic genes (COL18A1, COL4A3, F2, IFN- $\gamma$, and TGF$\beta 1 / 3$ ). Extracellular matrix-related proteins (FMOD, OSTP, and COBA1) were also higher in diabetic secretome. These data indicate that BM-MSCs from DM2 rats have a unique secretome with distinct angiogenic properties and provide new insights into the role of BM-MSCs in aberrant angiogenesis in the diabetic milieu.

The hyperglycemic milieu may also adversely impact MSC functionality. Therefore, AT-MSC extracted from Zucker diabetic fatty rats exhibited downregulation of markers of pluripotency (lower capacity of osteogenic and endothelial differentiation in vitro) and self-renewal, which may compromise the efficiency of direct self-repair and autologous cell therapy [121]. In addition, these cells exhibited loss of viability, impairment of capillary-like tube formation in Matrigel, decreased expression of stemness genes, signaling pathways important for stem cell maintenance
(Nocth1, Notch2, Wnt1, and Dhh) genes, and cell trafficking (CXCL2 and CXCR4) genes, as well as decreased angiogenesis in vivo [121].

Likewise, MSCs extracted from rodents with DM2 or large animals with metabolic syndrome have morphological abnormalities (larger number of degenerated mitochondria and marked expansion of endoplasmic reticulum), less proliferative potential associated with an increase in doubling time, alteration in gene expression (downregulation of growth factors IGF-1 and EGF, and angiogenic factors TBX1 and TBX5, and upregulation of proinflammatory genes IFN- $\gamma$ and IL- $1 \beta$. IL-2, regulated on activation normal T cell expressed and secreted (RANTES), TNF- $\alpha$, as well as alpha muscle actin, which represents the stress fiber, and XBP-1, which represents endoplasmic reticulum stress), greater senescence, lower viability and homing capacity, increased apoptosis, and a reduction in clonogenic and multidifferentiation potentials $[115,122,123]$. Conversely, BMMSCs from diabetic rodents may preserve their multipotent capacity when compared to nondiabetic animals [124].

Of importance, studies with longer duration are required to improve our understanding on the safety profile of MSCbased therapy, such as the cytogenetic aberrations observed during the propagation of these cells in culture. In MSCs derived from mice (C57BL/6 and BALB/c), such aberrations were observed after several passages in vitro [125], as well as their malignant transformation in vivo, either after injection [126] or promoting the growth of a preexisting tumor [127]. The injection of human (xenogeneic) MSCs in murine models may be associated with the formation of tumors in these animals, as well as with other structural changes, such as chronic jejunitis and villous atrophy, during a threemonth follow-up period [128].

\subsection{Autologous-Derived MSC for Halting the Progression of} DKD in Humans: Advantages and Drawbacks. BM-MSCs are the main source of autologous cell transplantation for various diseases including DM-related micro- and macrovascular complications [129]. Therapy with autologous MSCs is of great interest and has advantages for the patient, as these cells are readily available. MSC-based therapy is based on the extraction of these cells from the patient, expansion in vitro, and injection back into the patient, thus avoiding complications resulting from graft rejection and/or the need for an immunosuppressive regimen. Therefore, while patient-derived (autologous) MSC may be the safer choice in terms of avoiding unwanted immune response, factors including donor comorbidities (DM, chronic kidney disease, hypertension, and others) and aging may preclude those cells from use.

Notwithstanding recent promising results with MSC therapy in several diseases, moving the concept forward toward the DKD setting should be critically assessed by looking for intrinsic MSC abnormalities caused by the hyperglycemic milieu, which may adversely affect their therapeutic potential in diabetic patients. Thus, AT-MSCs extracted from diabetic individuals have a greater capacity for adipogenic differentiation, but less chondrogenic and osteogenic differentiation [130, 131]. Conversely, BM-MSCs from diabetic 
TABLE 1: Preclinical studies in small and large animals to verify the therapeutic potential of MSCs in DKD.

\begin{tabular}{|c|c|c|c|c|c|c|}
\hline MSC type & MSC source & Model of DKD and groups & $\begin{array}{c}\text { Number of } \\
\text { injections/route } \\
\text { of delivery }\end{array}$ & $\begin{array}{c}\text { Number of } \\
\text { cells } \\
\text { injected }\end{array}$ & Results & Ref \\
\hline Xenogeneic & h-BM & $\begin{array}{c}\text { STZ-induced DM1 in } \\
\text { NOD/scid mice: control, DKD, } \\
\text { DKD+hMSC }\end{array}$ & $\begin{array}{l}\text { Single dose, } \\
\text { intracardiac }\end{array}$ & $2.5 \times 10^{6}$ & $\begin{array}{c}\text { DKD+hMSC versus DKD: } \\
\uparrow \text { Pancreatic insulin content } \\
\text { and islet cell number } \\
\downarrow \text { Renal macrophage } \\
\text { infiltration } \\
\text { Improvement in renal } \\
\text { histology }\end{array}$ & [98] \\
\hline Syngeneic & $\mathrm{BM}$ & $\begin{array}{c}\text { STZ-induced DM1 in C57BL/6 } \\
\text { mice: DKD+vehicle and DKD } \\
+ \text { MSC }\end{array}$ & Single dose, IV & $0.5 \times 10^{6}$ & $\begin{array}{c}\text { DKD+MSCs versus DKD: } \\
\downarrow \text { FBG } \\
\downarrow \text { Albuminuria and glycosuria } \\
\text { Improvement in renal and } \beta \text { - } \\
\text { cell histology }\end{array}$ & [99] \\
\hline Syngeneic & $\mathrm{BM}$ & $\begin{array}{c}\text { STZ-induced DM1 in C57BL/6 } \\
\text { mice: control, DKD+vehicle, } \\
\text { DKD+MSC }\end{array}$ & $\begin{array}{l}\text { Two doses (20 } \\
\text { days apart), IV }\end{array}$ & $0.5 \times 10^{6}$ & $\begin{array}{c}\text { DKD+MSCs versus DKD: } \\
\downarrow \text { Albuminuria } \\
\text { Improvement in renal } \\
\text { histology } \\
\text { No improvement in } \beta \text {-cell } \\
\text { function and histology }\end{array}$ & {$[100]$} \\
\hline Syngeneic & $\mathrm{BM}$ & $\begin{array}{l}\text { STZ-induced DM1 in Sprague- } \\
\text { Dawley rats: DKD, DKD } \\
\text { +MSC, DKD+CSA, DKD } \\
\text { +MSC+CSA (MSCA) }\end{array}$ & $\begin{array}{l}\text { Single dose, } \\
\text { intracardiac }\end{array}$ & $2 \times 10^{6}$ & 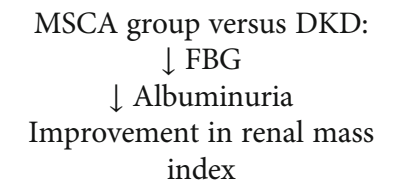 & [101] \\
\hline Autologous & AT & $\begin{array}{l}\text { STZ-induced DM1 in diabetes } \\
\text { Sprague-Dawley rats: control, } \\
\text { DKD+vehicle, DKD+AT-MSC }\end{array}$ & Single dose, IV & $1 \times 10^{7}$ & $\begin{array}{c}\text { DKD+AT-MSCs versus DKD: } \\
\downarrow \text { Renal p-p-38, p-ERK, and p- } \\
\text { JNK } \\
\downarrow \text { Renal MDA and carbonyl } \\
\text { protein } \\
\downarrow \text { Renal TNF- } \alpha \text {, IL-1 } \beta \text {, IL-6 } \\
\downarrow \text { Renal MnSOD and CuZn- } \\
\text { SOD }\end{array}$ & [102] \\
\hline Xenogeneic & h-UCB & $\begin{array}{c}\text { STZ-induced DM1 in Sprague- } \\
\text { Dawley rats: control, DKD, } \\
\text { DKD+h-UCB-SC }\end{array}$ & Single dose, IV & $1 \times 10^{6}$ & $\begin{array}{c}\text { DKD }+\mathrm{h}-\mathrm{UCB}-\mathrm{SCs} \text { versus } \\
\text { DKD: } \\
\downarrow \text { FBG } \\
\downarrow \text { Albuminuria } \\
\downarrow \text { Renal fibronectin, } \alpha \text {-SMA } \\
\uparrow \text { Renal E-cadherin }\end{array}$ & [103] \\
\hline Xenogeneic & h-UCB & $\begin{array}{l}\text { STZ-induced DM1 in Sprague- } \\
\text { Dawley rats: control, DKD, } \\
\text { DKD+h-UCB-SC }\end{array}$ & Single dose, IV & $5 \times 10^{5}$ & $\begin{array}{c}\text { DKD+h-UCB-SCs versus } \\
\text { DKD: } \\
\leftrightarrow \text { FBG } \\
\leftrightarrow \text { Albuminuria } \\
\text { Improvement in renal } \\
\text { histology } \\
\downarrow \text { Renal TGF- } \beta 1, \alpha \text {-SMA } \\
\uparrow \text { Renal E-cadherin, BMP-7 }\end{array}$ & [104] \\
\hline \multirow[t]{2}{*}{ Syngeneic } & $\mathrm{BM}$ & $\begin{array}{l}\text { STZ-induced DM1 in Sprague- } \\
\text { Dawley rats: control, DKD } \\
\text { +MSC, DKD+medium }\end{array}$ & $\begin{array}{l}\text { Single dose, left } \\
\text { renal artery }\end{array}$ & $2 \times 10^{6}$ & $\begin{array}{c}\text { DKD+MSCs versus DKD } \\
+ \text { medium: } \\
\leftrightarrow \text { FBG } \\
\downarrow \text { Kidney weight, kidney/body } \\
\text { weight, creatinine clearance } \\
\downarrow \text { Albuminuria } \\
\text { Improvement in renal } \\
\text { histology } \\
\uparrow \text { Renal nephrin, podocin, } \\
\text { VEGF, BMP-7 }\end{array}$ & [105] \\
\hline & $\mathrm{BM}$ & & Single dose, IV & & & [106] \\
\hline
\end{tabular}


TABle 1: Continued.

\begin{tabular}{|c|c|c|c|c|c|c|}
\hline MSC type & MSC source & Model of DKD and groups & $\begin{array}{c}\text { Number of } \\
\text { injections/route } \\
\text { of delivery }\end{array}$ & $\begin{array}{c}\text { Number of } \\
\text { cells } \\
\text { injected }\end{array}$ & Results & Ref \\
\hline $\begin{array}{l}\text { Syngeneic, } \\
\text { UTDM }\end{array}$ & & $\begin{array}{l}\text { STZ-induced DM1 in Sprague- } \\
\text { Dawley rats: control, DKD } \\
\text { +vehicle, DKD+UTMD, DKD } \\
\text { +MSC, DKD+MSC+UTMD }\end{array}$ & & $1 \times 10^{6}$ & $\begin{array}{c}\text { DKD+MSC and DKD+MSC } \\
\text { +UTMD versus DKD+vehicle } \\
\text { and DKD+UTMD: } \\
\downarrow \text { FBG } \\
\uparrow \text { Plasma insulin } \\
\text { Attenuated } \beta \text {-cell damage } \\
\downarrow \text { Albuminuria } \\
\downarrow \text { Renal TGF- } \beta 1 \\
\uparrow \text { Renal synaptopodin, IL-10 } \\
{ }^{*} \text { After UTMD: MSC homing } \\
\text { was increased to kidneys }(\sim 2 \mathrm{x})\end{array}$ & \\
\hline Syngeneic & $\mathrm{BM}$ & $\begin{array}{c}\text { STZ-induced DM1 in Wistar } \\
\text { rats: control, DKD+vehicle, } \\
\text { DKD+MSC }\end{array}$ & $\begin{array}{c}2 \text { doses (1 week } \\
\text { apart), IV }\end{array}$ & $2 \times 10^{6}$ & $\begin{array}{c}\text { DKD+MSCs versus DKD: } \\
\downarrow \text { FBG } \\
\downarrow \text { Albuminuria } \\
\downarrow \text { Creatinine clearance } \\
\text { Improvement in renal } \\
\text { histology } \\
\downarrow \text { Renal MCP-1, ED-1, IL-1 } \beta \text {, } \\
\text { IL-6, TNF- } \alpha \\
\uparrow \text { Renal HGF }\end{array}$ & [107] \\
\hline Syngeneic & $\mathrm{BM}$ & $\begin{array}{l}\text { STZ-induced DM1 in Wistar } \\
\text { rats: DKD, DKD+MSC, DKD } \\
\text { +insulin, DKD+probucol }\end{array}$ & $\begin{array}{c}2 \text { doses (1 week } \\
\text { apart), IV }\end{array}$ & $2 \times 10^{6}$ & $\begin{array}{c}\text { DKD+MSCs versus DKD: } \\
\downarrow \text { FBG } \\
\downarrow \text { Albuminuria } \\
\downarrow \text { Creatinine clearance } \\
\downarrow \text { Kidney/body weight } \\
\text { Improvement in renal } \\
\text { histology } \\
\downarrow \text { Renal fibronectin, collagen I, } \\
\text { TGF- } \beta 1 \text {, MDA content, ROS } \\
\text { fluorescence } \\
\uparrow \text { Renal SOD activity } \\
\downarrow \text { Cellular glucose uptake } \\
\text { mediated by GLUT1 in } \\
\text { kidneys }\end{array}$ & {$[108]$} \\
\hline Syngeneic & $\mathrm{BM}$ & $\begin{array}{l}\text { STZ-induced DM1 in albino } \\
\text { rats: control, DKD, DKD } \\
\text { +vehicle, DKD+MSC }\end{array}$ & Single dose, IV & $1 \times 10^{6}$ & $\begin{array}{c}\text { DKD+MSCs versus DKD: } \\
\downarrow \text { FBG } \\
\downarrow \text { Albuminuria } \\
\downarrow \text { Body weight } \\
\downarrow \text { Serum creatinine and urea } \\
\uparrow \text { Renal VEGF and } \\
\text { antiapoptotic bcl } 2 \\
\downarrow \text { Renal TNF- } \alpha \text {, proapoptotic } \\
\text { Bax, TGF- } \beta \\
\text { Improvement in renal } \\
\text { histology }\end{array}$ & {$[109]$} \\
\hline Syngeneic & $\mathrm{BM}$ & $\begin{array}{l}\text { STZ-induced DM1 in Wistar } \\
\text { rats: control, DKD+vehicle, } \\
\text { DKD+MSC }\end{array}$ & $\begin{array}{c}2 \text { doses (1 week } \\
\text { apart), IV }\end{array}$ & $2 \times 10^{6}$ & $\begin{array}{c}\text { DKD+MSCs versus DKD: } \\
\downarrow \text { FBG } \\
\downarrow \text { Albuminuria } \\
\downarrow \text { Kidney/body weight } \\
\downarrow \text { Creatinine clearance } \\
\text { Improvement in renal } \\
\text { histology } \\
\downarrow \text { Renal collagen I, collagen IV, } \\
\alpha \text {-SMA, TGF- } \beta \text {, P- } \\
\text { smad3/smad2/3 } \\
\uparrow \text { Renal E-cadherin, BMP-7 }\end{array}$ & [47] \\
\hline
\end{tabular}


TABle 1: Continued.

\begin{tabular}{|c|c|c|c|c|c|c|}
\hline MSC type & MSC source & Model of DKD and groups & $\begin{array}{l}\text { Number of } \\
\text { injections/route } \\
\text { of delivery }\end{array}$ & $\begin{array}{l}\text { Number of } \\
\text { cells } \\
\text { injected }\end{array}$ & Results & Ref \\
\hline Syngeneic & $\begin{array}{l}\text { BM } \\
{ }^{*} \text { SDF-1-loaded } \\
\text { microbubbles }\end{array}$ & $\begin{array}{c}\text { STZ-induced DM1 in Sprague- } \\
\text { Dawley rats: DKD+vehicle, } \\
\text { DKD+UTMD, DKD+UTMD } \\
+ \text { MSC-SDF-1 }\end{array}$ & Single dose, IV & $1 \times 10^{6}$ & $\begin{array}{c}\text { DKD+UTMD+MSC-SDF-1 } \\
\text { versus DKD: } \\
\text { Improvement in renal } \\
\text { histology } \\
\uparrow \text { MSC engraftment with SDF- } \\
1 \text { (7-fold versus control and } \\
1.6 \text {-fold versus UTDM) }\end{array}$ & [110] \\
\hline Syngeneic & $\mathrm{BM}$ & $\begin{array}{c}\text { STZ-induced DM1 in C57BL/6 } \\
\text { mice: DKD+vehicle, DKD } \\
+ \text { MSC }\end{array}$ & Single dose, IV & $0.5 \times 10^{6}$ & $\begin{array}{c}\text { DKD+MSCs versus DKD: } \\
\downarrow \text { Kidney } \\
\downarrow \text { Kidney/body weight } \\
\downarrow \text { Serum creatinine, urea, and } \\
\text { plasma cystatin C } \\
\downarrow \text { Renal collagen I and } \\
\text { fibronectin } \\
\downarrow \text { Renal tubular apoptotic } \\
\text { index, ROS total, lipid } \\
\text { peroxidation, oxidative protein } \\
\text { damage, F4/80-positive cells } \\
\uparrow \text { Renal nephrin, tubular Ki67 } \\
\text { proliferation index } \\
\uparrow \text { Plasma bFGF, EGF, HGF, IL- } \\
\text { 6, and IL-10 } \\
\text { Improvement in renal } \\
\text { histology }\end{array}$ & [111] \\
\hline Syngeneic & AT & $\begin{array}{l}\text { STZ-induced DM1 in Sprague- } \\
\text { Dawley rats: control, DKD, } \\
\text { DKD+vehicle, DKD+MSC }\end{array}$ & Single dose, IV & $1 \times 10^{7}$ & $\begin{array}{c}\text { DKD+MSCs versus DKD: } \\
\text { Improvement in renal } \\
\text { histology } \\
\downarrow \text { Kidney apoptosis (TUNEL, } \downarrow \\
\text { Bax and } \uparrow \text { Bcl2), expression of } \\
\text { Wnt1, Wnt3a, Snail, active } \beta \text { - } \\
\text { catenin } \\
\uparrow \text { Renal klotho }\end{array}$ & {$[49]$} \\
\hline Syngeneic & $\mathrm{BM}$ & $\begin{array}{c}\text { STZ-induced DM1 in Sprague- } \\
\text { Dawley rats: control, DKD, } \\
\text { DKD+MSC }\end{array}$ & Single dose, IV & $2 \times 10^{6}$ & $\begin{array}{c}\text { DKD }+ \text { MSC versus DKD: } \\
\leftrightarrow \text { FBG } \\
\downarrow \text { Albuminuria } \\
\downarrow \text { Kidney weight } \\
\downarrow \text { Serum creatinine } \\
\downarrow \text { Renal PAI- } 1, \text { TGF- } \beta 1, \\
\text { Smad3 }\end{array}$ & [112] \\
\hline Xenogeneic & $\begin{array}{l}\text { h-BM (DM1 } \\
\text { and normal } \\
\text { individuals) }\end{array}$ & $\begin{array}{l}\text { STZ-induced DM1 in C57BL/6 } \\
\text { mice: DKD+DM1-MSC, DKD } \\
\text { +control MSC, DKD+vehicle }\end{array}$ & $\begin{array}{l}\text { Single dose, } \\
\text { intrasplenic }\end{array}$ & $1 \times 10^{6}$ & $\begin{array}{c}\text { DKD+MSC versus DKD: } \\
\downarrow \text { FBG }(\sim 70 \% \text { of mice }) \\
\uparrow \text { Serum insulin } \\
\text { Improvement in glucose } \\
\text { tolerance test } \\
\text { Improvement in pancreatic } \\
\text { inflammation }(\downarrow \text { IL-2 and INF- } \\
\gamma) \text { and } \beta \text {-cell function }\end{array}$ & [113] \\
\hline $\begin{array}{l}\text { Xenogeneic } \\
\text { (Lewis and SD- } \\
\text { Tg rats -> } \\
\text { C57BL/6J and } \\
\text { C57BL/6-Tg } \\
\text { mice) }\end{array}$ & $\mathrm{BM}$ & $\begin{array}{c}\text { STZ-induced DM1 and HFD- } \\
\text { induced DM2 in C57BL/6J and } \\
\text { C57BL/6-Tg mice: } \\
\text { Control, STZ+vehicle, STZ } \\
\text { +MSC, STZ+MSC-CM } \\
\text { Control, HFD+vehicle, HFD } \\
\text { +MSC, HFD+MSC-CM }\end{array}$ & $\begin{array}{l}\text { STZ model: } 2 \\
\text { doses ( } 4 \text { weeks } \\
\text { apart) } \\
\text { HFD model: } 4 \\
\text { doses ( } 2 \text { weeks } \\
\text { apart) } \\
\text { IV }\end{array}$ & $\begin{array}{l}1 \times 10^{4} \\
\text { MSC/body } \\
\text { weight }\end{array}$ & $\begin{array}{c}\text { STZ model: STZ+MSC and } \\
\text { STZ+CM-MSC versus STZ } \\
+ \text { vehicle } \\
\text { Improvement in renal } \\
\text { histology } \\
\downarrow \text { FBG: all groups versus } \\
\text { control } \\
\downarrow \text { Renal TNF- } \alpha \text {, ICAM-1, p- } \\
\text { p38-MAPK }\end{array}$ & {$[50]$} \\
\hline
\end{tabular}


TABle 1: Continued.

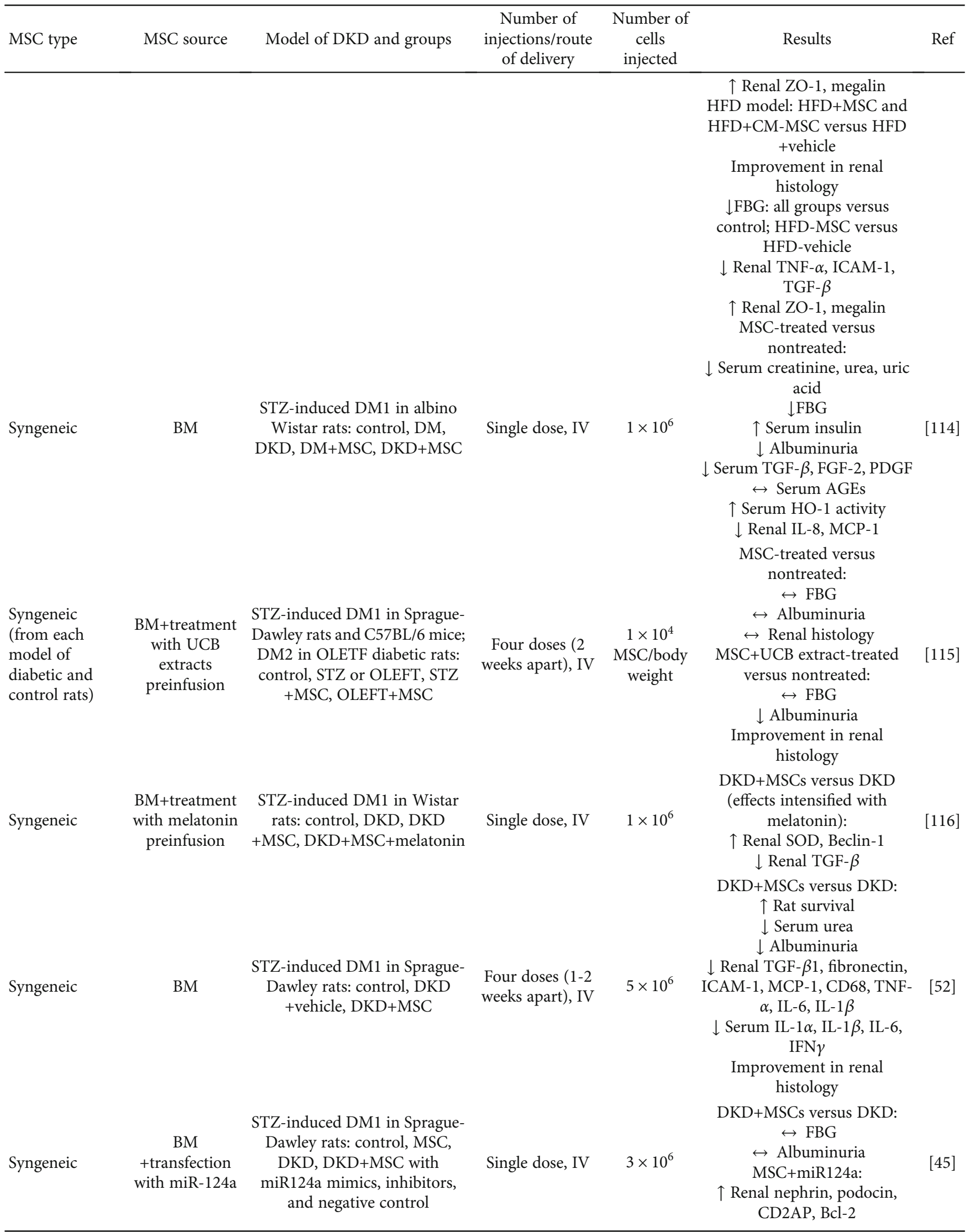


TABle 1: Continued.

\begin{tabular}{|c|c|c|c|c|c|c|}
\hline MSC type & MSC source & Model of DKD and groups & $\begin{array}{c}\text { Number of } \\
\text { injections/route } \\
\text { of delivery }\end{array}$ & $\begin{array}{c}\text { Number of } \\
\text { cells } \\
\text { injected }\end{array}$ & Results & Ref \\
\hline $\begin{array}{l}\text { Xenogeneic } \\
\text { (human -> } \\
\text { monkeys) }\end{array}$ & $\mathrm{BM}$ & $\begin{array}{c}\text { STZ-induced DM1 in } \\
\text { cynomolgus monkeys (Macaca } \\
\text { fascicularis) treated with } \\
\text { insulin glargine and glulisine } \\
\text { +acute ischemia-reperfusion } \\
\text { injury: control, DKD, DKD } \\
+ \text { MSC }\end{array}$ & $\begin{array}{l}\text { Single dose; intra- } \\
\text { arterial } \\
\text { (suprarenal } \\
\text { aorta) }\end{array}$ & $\begin{array}{l}5 \times 10^{6} \\
\text { cells } / \mathrm{kg}\end{array}$ & $\begin{array}{c}\downarrow \text { Renal TGF- } \beta 1 \text {, collagen I } \\
\text { and III, caspase- } 3 \text {, Bax } \\
\text { DKD+MSCs versus DKD: } \\
\leftrightarrow \text { Serum creatinine, urea, } \\
\text { TNF- } \alpha \text {, IFN- } \gamma \\
\leftrightarrow \text { Albuminuria } \\
\leftrightarrow \text { Urinary NGAL, GST- } \alpha, \\
\text { and TIMP- } 1 \\
\text { Improvement in renal } \\
\text { histology ( } \downarrow \text { necrosis) }\end{array}$ & [117] \\
\hline Syngeneic & $\begin{array}{l}\text { Amniotic liquid } \\
\text { (adenovirus } \\
\text { SIRT3 } \\
\text { overexpression) }\end{array}$ & $\begin{array}{l}\mathrm{db} / \mathrm{db} \text { mice: wild type, control, } \\
\text { DKD+adenovirus control, } \\
\text { DKD+adenovirus-SIRT3 }\end{array}$ & $\begin{array}{l}\text { Single dose, } \\
\text { intraparenchymal }\end{array}$ & $3 \times 10^{6}$ & $\begin{array}{c}\text { DKD versus DKD+SIRT3: } \\
\downarrow \text { Body weight } \\
\downarrow \text { FBG, serum insulin, C- } \\
\text { peptide, glucagon, HbA1c } \\
\downarrow \text { Serum creatinine, urea } \\
\downarrow \text { Serum TNF- } \alpha \text {, IL-6, MCP-1 } \\
\downarrow \text { Systolic blood pressure } \\
\downarrow \text { Albuminuria } \\
\downarrow \text { Kidney weight, oxidative } \\
\text { stress, collagen I/III/IV } \\
\text { deposition, MMP9, TGF- } \beta \\
\text { Improvement in renal } \\
\text { histology }\end{array}$ & [118] \\
\hline Syngeneic & $\mathrm{BM}$ & $\begin{array}{l}\text { STZ-induced DM1 in Sprague- } \\
\text { Dawley rats: control, DKD } \\
\text { +vehicle, DKD+MSC, DKD } \\
\text { +MSC+WRW4 (1 mg/kg), } \\
\text { DKD+LXA4 (10 mg/kg), DKD } \\
\text { +LXA4+WRW4 }\end{array}$ & $\begin{array}{c}\text { Two doses (1 } \\
\text { week apart), IV }\end{array}$ & $5 \times 10^{6}$ & $\begin{array}{c}\text { DKD+MSCs versus DKD: } \\
\uparrow \text { Rat survival } \\
\leftrightarrow \text { FBG } \\
\downarrow \text { Serum creatinine and urea } \\
\downarrow \text { Glycosuria, albuminuria } \\
\uparrow \text { Renal LXA4 } \\
\downarrow \text { Renal TGF- } \beta 1, \text { p-SMAD2/3 } \\
\downarrow \text { Serum TNF- } \alpha \text {, IL-6, IL-8, } \\
\text { IFN- } \gamma \text { (LXA4 treatment } \\
\text { exhibited similar findings } \\
\text { when compared to MSC, } \\
\text { which was abrogated by } \\
\text { WRW4 treatment) }\end{array}$ & {$[48]$} \\
\hline $\begin{array}{l}\text { Allogeneic } \\
\text { (from CAG- } \\
\text { EGFP.SD-Tg } \\
\text { rats) }\end{array}$ & AT & $\begin{array}{l}\text { Spontaneously diabetic Torii } \\
\text { (SDT) fatty rats (SDT.Cg- } \\
\text { Lepfa/JttJcl)+unilateral } \\
\text { nephrectomy: control; DKD } \\
\text { +MSC suspension via IV route; } \\
\text { DKD+MSC sheets } \\
\text { transplanted directly into the } \\
\text { kidney }\end{array}$ & $\begin{array}{l}\text { Single dose, IV or } \\
\text { cell sheets } \\
\text { transplanted } \\
\text { directly into the } \\
\text { kidney }\end{array}$ & $\begin{array}{l}6 \times 10^{6} / \mathrm{ml} \\
\text { via IV } \\
\text { route and } \\
\text { cell sheets }\end{array}$ & $\begin{array}{c}\text { DKD+cell sheets versus DKD } \\
+ \text { MSC via IV route and DKD: } \\
\downarrow \text { Albuminuria, proteinuria, } \\
\text { and urinary L-FABP, KIM-1, } \\
\text { IL-6 } \\
\text { Improvement in renal } \\
\text { histology } \\
\text { DKD+cell sheets and DKD } \\
\text { +MSC via IV route versus } \\
\text { DKD: } \\
\downarrow \text { Urinary podocalyxin and } \\
\text { TNF- } \alpha\end{array}$ & {$[90]$} \\
\hline $\begin{array}{l}\text { Xenogeneic } \\
\text { (human -> } \\
\text { macaques) }\end{array}$ & UCB & $\begin{array}{c}\text { STZ-induced DM1 in rhesus } \\
\text { macaques+high-fat and high- } \\
\text { salt diet (for } 2 \text { years): control; } \\
\text { DKD; DKD+MSC }\end{array}$ & $\begin{array}{c}4 \text { doses (2 weeks } \\
\text { apart), IV }\end{array}$ & $2 \times 10^{6} / \mathrm{kg}$ & $\begin{array}{c}\text { DKD+MSCs versus DKD: } \\
\downarrow \text { FBG, insulin requirement } \\
\downarrow \text { Serum creatinine and BUN } \\
\uparrow \text { eGFR } \\
\downarrow \text { Albuminuria } \\
\downarrow \text { Renal IL- } 1 \beta, \text { IL-16, TNF- } \alpha, \\
\text { CTGF, SGLT2 } \\
\uparrow \text { Renal IL-6 } \\
\downarrow \text { Serum IFN- } \gamma \text {, TNF- } \alpha \text {, IL- } 1 \beta,\end{array}$ & {$[44]$} \\
\hline
\end{tabular}


TABLE 1: Continued.

\begin{tabular}{|c|c|c|c|c|c|c|}
\hline MSC type & MSC source & Model of DKD and groups & $\begin{array}{c}\text { Number of } \\
\text { injections/route } \\
\text { of delivery }\end{array}$ & $\begin{array}{c}\text { Number of } \\
\text { cells } \\
\text { injected }\end{array}$ & Results & Ref \\
\hline $\begin{array}{l}\text { Xenogeneic } \\
\text { (human -> } \\
\text { mice) }\end{array}$ & $\mathrm{UCB}$ & $\begin{array}{l}\text { Unilateral nephrectomy+STZ- } \\
\text { induced DM1 in CD1 mice }\end{array}$ & $\begin{array}{c}3 \text { doses (4 weeks } \\
\text { apart), IV }\end{array}$ & $5 \times 10^{5}$ & $\begin{array}{c}\text { IL-5, IL-12p70, IL-15, IL-16 } \\
\text { Improvement in renal } \\
\text { histology } \\
\text { DKD+MSCs versus DKD: } \\
\leftrightarrow \text { Serum glucose } \\
\downarrow \text { Serum creatinine and BUN } \\
\downarrow \text { Albuminuria } \\
\downarrow \text { Renal mRNA desmim, } \alpha \text { - } \\
\text { SMA, Fn1, Kim-1, NGAL, } \\
\text { MCP-1, VCAM-1, ICAM-1, } \\
\text { IL-1b, TNF- } \alpha, \text { IL-6, iNOS } \\
\uparrow \text { Renal mRNA arginine } 1 \\
\text { Improvement in renal } \\
\text { histology }\end{array}$ & [53] \\
\hline
\end{tabular}

MSCs: mesenchymal stem cells; BM-MSC: bone marrow-derived MSCs; h-BM-MSC: human bone marrow-derived MSC; AT-MSC: adipose tissue-derived MSCs; h-UCB-SCs: human umbilical cord blood-derived stem cells; MSC-CM: MSC-conditioned medium; DM: diabetes mellitus; DKD: diabetic kidney disease; AGEs: advanced glycation end products; BMP-7: bone morphogenic protein-7; CSA: cyclosporine; EGF: epidermal growth factor; FBG: fasting blood glucose; bFGF: basic fibroblast growth factor; Fn1: fibronectin-1; GST- $\alpha$ : glutathione S-transferase- $\alpha$; HFD: high-fat diet; HGF: hepatocyte growth factor; HO-1: heme-oxygenase-1; ICAM-1: intercellular adhesion molecule-1; iNOS: inducible nitric oxide synthase; IL: interleukin; IFN- $\gamma$ : interferon- $\gamma$; IV: intravenous; KIM-1: kidney injury molecule-1; LETO: Long-Evans Tokushima Otsuka rats; L-FABP: liver-type fatty acid binding protein; LXA4: lipoxin A4; MDA: malondialdehyde; miR: microRNA; MCP-1: monocyte chemoattractant protein-1; MMP: matrix metalloproteinase; NGAL: neutrophil-gelatinase associated lipocalin; OLETF: Otsuka Long-Evans Tokushima Fatty diabetic rats; PAI-1: plasminogen activator inhibitor-1; PDGF: platelet-derived growth factor; ROS: reactive oxygen species; SDF-1: stromal-derived factor-1; SIRT3: sirtuin 3; SOD: superoxide dismutase; $\alpha$-SMA: $\alpha$-smooth muscle actin; STZ: streptozotocin; TGF- $\alpha$ : transforming growth factor $\alpha$; TGF- $\beta 1$ : transforming growth factor $\beta 1$; TIMP-1: tissue inhibitor metalloproteinase-1; TNF- $\alpha$ : tumor necrosis factor- $\alpha$; UTMD: ultrasound-targeted microbubble destruction; VCAM-1: vascular cell adhesion molecule-1; VEGF: vascular endothelial growth factor; ZO-1: zonula occludens-1.

individuals preserve their multipotent capacity [113]. Therefore, the source of MSC may play a critical role in decisionmaking for treating diabetic individuals. AT-MSCs isolated from the ischemic limb of diabetic patients seem to be less potent when compared phenotypically and functionally to control nondiabetic counterparts with no signs of limb ischemia [132]. To note, $40 \%$ of diabetic and $20 \%$ of nondiabetic AT-MSC samples displayed high expressions of fibroblast marker, which inversely correlated with the expression of CD105. In diabetic patients, significantly decreased expression of VEGF and CXCR4 was verified in fibroblastpositive AT-MSCs when compared to their fibroblastnegative counterparts, which may negatively affect angiogenic and homing capacity mediated by AT-MSCs, respectively [132]. Reduced osteogenic differentiation and the downregulation of chemokine CXCL12 were also observed in fibroblast-negative diabetic AT-MSCs. Both diabetic and nondiabetic AT-MSCs were able to differentiate into adipocytes and chondrocytes, yet not exhibiting islet-like cell differentiation in that study [132]. Importantly, in vitro studies documented the differentiation potential of human AT-MSCs into islet-like cells when these cells were obtained from healthy individuals who underwent abdominoplasty or liposuction [133-135]. Transdifferentiated cells exhibit positive staining for dithizone, increased expression of islet cellrelated genes (Pdx-1, Isl1, Ngn3, NeuroD1, Pax4, and GLUT2), and insulin secretion when these cells were challenged with high concentrations of glucose.
Not only the source of MSCs but also the type of DM may affect the therapeutic potential of MSCs. MSCs extracted from DM1 individuals exhibited preserved morphology, growth kinetics, multipotency, and proliferative, immunomodulatory, immunosuppressive, and migratory capacities [113, 136].

In contrast, MSCs extracted from individuals with DM2 have greater senescence, lower viability, increased apoptosis (increased proapoptotic gene expression, such as p53, caspase 9, and BAX, and low antiapoptotic gene expression, such as Bcl-2), less proliferative potential associated with increased doubling time, and a reduction in angiogenic potential [130, 137].

CD105 (endoglin) is associated with angiogenesis [138], and its positivity in AT-MSC leads to higher rates of proliferation [139]. Therefore, reduced CD105 expression and proliferation of AT-MSC in DM2 individuals indicate an impairment of angiogenesis of these cells [137]. Conversely, CD105 negativity in human AT-MSC indicates a more efficient immunomodulatory capacity when compared to CD105-positive cells [140].

In line with the derangement observed in MSC-induced angiogenesis of rodents, AT-MSCs extracted from DM2 individuals with critical limb ischemia are dysfunctional, e.g., they exhibited a reduction in fibrinolytic activity and an increase in prothrombotic activity and PAI- levels. Those cells also possess lower efficiency of proliferation, migration, and CFU-f assay, as well as derangement in the PDGF (platelet-derived growth factor) signaling pathway [131]. PDGF 
signaling is known to modulate essential MSC processes, such as differentiation, migration, and proliferation, as well as coagulation and fibrinolysis systems. In addition, AT-MSC obtained from diabetic patients exhibited a decrease in angiogenic potential (lower level of VEGF expression and cell proliferation) when compared to healthy donors in a murine model of an ischemic flap [141]. Notably, VEGF and HGF secretion, tubulogenesis, and cell proliferation in diabetic conditioned media were increased in response to hypoxic stimuli, and it was similar to those of control cells. These findings may be important in the context of future study of autologous cellbased therapy in diabetic patients and indicate that hypoxiamediated preconditioning may be a useful strategy for increasing the therapeutic potential of diabetic MSCs.

The change in the secretome of diabetic MSCs grown even under normoglycemic conditions is related to the development of metabolic memory, a process in which hypomethylation in gene promoters leads to dysregulation of gene expression and implies the persistence of DM-related complications even when glucose returns to normal levels. That effect is supported by studies that show changes in glucose metabolism in diabetic MSCs and by the fact that their functional capacities were not altered by normalization of glucose levels in vitro $[120,122]$.

Therefore, serum obtained from DM2 individuals may increase the BM-MSC proliferation in vitro rate, and $\mathrm{HbAlc}$ levels may play a role in that effect, indicating that higher rates of proliferation occur when $\mathrm{HbA1c}$ levels were $8-10 \%$ (versus $\mathrm{HbA} 1 \mathrm{c}<6.5 \%$ ), yet serum derived from individuals with $\mathrm{HbA} 1 \mathrm{c}>10 \%$ exhibited a decrease in MSC proliferation [142]. On the other hand, diabetic serum decreased osteogenic differentiation in a concentration-dependent manner of HbA1c levels. These findings indicate the impact of the hyperglycemia control on MSC function and suggest that diabetic-derived MSC may be adversely affected in the diabetic milieu. A key aspect in that setting includes the adequate treatment of DM in order to support a better therapeutic potential of MSCs. Not only DM but also other chronic diseases, such as CKD, may impair MSC functionality. Autologous AT-MSCs obtained from CKD individuals (stages 3 and 4 ), when injected intravenously $\left(1 \times 10^{6} / \mathrm{kg}\right)$, exhibited a safety profile and contributed to decreasing proteinuria, yet not modifying eGFR in six patients [143]. Other progenitor cells, such as endothelial progenitor cells, are affected by uremia regardless of the presence of DM [144].

Notably, BM-MSC of newly diagnosed ( $<6$ weeks) DM1 individuals (all males, $23.2 \pm 2.9$ years) presented similar morphology, immunophenotype, differentiation potential, gene expression of immunomodulatory molecules, and in vitro immunosuppressive capacity when compared to normal individuals [113]. However, the HGF gene was significantly downregulated in DM1-derived MSC. When injected into STZ-induced diabetic mice, both DM1 and control MSCs lead to improvement in serum glucose and insulin and in pancreatic histology.

In line with these findings, Davies et al. compared BMMSC from individuals with newly diagnosed ( $<6$ weeks) DM1 ( $n=10$; mean age 22 years, range 18-35 years; 9 males), late stage of DM1 with severe renal failure $(n=12$, mean age
42 years, range 31-62 years; 7 males), and healthy BM donors ( $n=19$, mean age 37 years, range $21-70$ years; 13 males) [136]. They found that gene expression was different between healthy controls and late DM1 in relation to cytokine secretion, immunomodulatory activity, and wound healing potential. Despite these difference between BM-MSC, DM1derived MSCs did not demonstrate a significant difference from healthy controls in growth characteristics (CFU-f and doubling time), immunosuppressive activity, migratory capacity, or trophic properties at baseline and after exposure to proinflammatory cytokines IFN- $\gamma$ and TNF- $\alpha$ (similar activity of IDO and upregulation of IL-6, CXCL1, and CXCL6).

To further substantiate the benefits of autologous MSCbased therapy, preconditioning strategies are key aspects to preserve MSC function, such as hypoxia culture, as previously described [141]. In addition, antioxidant pretreatment (N-acetylcysteine and ascorbic acid 2-phosphate) of BMMSC from obese diabetic, B6.Cg-Lep ${ }^{\mathrm{ob}} / \mathrm{J}$ mice significantly reduced the excessive TNF- $\alpha$ response observed in diabetic mice and improved IL-10 secretion [145]. Iron chelator deferoxamine pretreatment of human AT-MSCs increases hypoxia inducible factor 1- $\alpha$ (HIF-1 $\alpha$ ), which led to an upregulation of angiogenic factors (VEGF and angiopoietin-1), neuroprotective factors (nerve growth factor, glial cell-derived neurotrophic factor, and neurotrophin-3), and cytokines with antiinflammatory activity (IL-4 and IL-5) [146]. Deferoxamine pretreatment also promoted the increase in the capacity of MSC secretome in vitro, which was associated with a decrease in neuron death. PDGF pretreatment of human AT-MSCs extracted from DM2 individuals rescued these cells from the diabetic phenotype by improving the proliferation, migration, and the capacity of clot lysing and repairing skin wound in an animal model [131].

Another approach to decrease abnormalities of BMMSC obtained from DM1 and DM2 animals is the coculture with human umbilical cord extracts (Wharton's jelly extract supernatant). Therefore, Wharton's jelly extract supernatant represents a cocktail of growth factors (IGF1, EGF, PDGF-AB, and b-FGF); components of extracellular matrixes (hyaluronic acid, collagen, and MUC-1), Lglutamate, and EXOs may also ameliorate proliferative capacity, motility, mitochondrial degeneration, endoplasmic reticular functions, and EXO secretion in both DM1- and DM2-derived BM-MSC, since that supernatant provide the physiological environment to preserve MSC properties and functionality [115]. These findings highlight the importance of seeking potential preconditioning approaches in the clinical setting. In addition, adenoviral transfection of Sirtuin3 in amniotic fluid stem cells protected these cells from high glucose-induced apoptosis by preserving mitochondrial function (increase in mitophagy, mitochondrial potential, respiratory function, and ATP levels, as well as a decrease in ROS, cytochrome c, and caspase activity) and ameliorating cell proliferation [118].

In conclusion, despite the fact that autologous MSCbased therapy has already been reported to ameliorate kidney injury, many difficulties must be overcome to successfully implement that therapy for treating DKD. Key aspects include the type of diabetes, time elapsed since the diagnosis 
due to cellular metabolic memory, and cell source, which may impair MSC functional properties.

In addition, some points are beyond the fact of choosing autologous or allogeneic MSCs for treating individuals with DM1 and DM2. Due to the expressive quantity of MSCs required to form a biobank and provide them to immediately infuse into patients, MSC expansion is a key aspect of cell therapy preparation. Both autologous and allogeneic MSCs cultured for a prolonged period may be affected by disturbance in the cellular structure and function. Chromosomal instability and aberrations have been shown in AT-MSCs after prolonged time in vitro [147], which leads to their discard. In contrast to these evidences, other researchers indicated MSC genetic stability during several passages in culture [148, 149]. Likewise, cell viability is another important characteristic to be assessed before administration, especially to avoid senescent cell infusion. Senescent cells have major alterations in the overall secretome components, leading to a switch from beneficial to a harmful profile [150].

Another important aspect that must be taken into account in cell therapy with MSCs is the fact that their beneficial effect can be neglected by the occurrence of adipogenic differentiation during long-term follow-up, which can contribute to glomerulosclerosis [78].

The malignant transformation of MSCs has not been described in clinical trials [151, 152]. As reviewed elsewhere, there are controversial data regarding protumorigenic effect of MSC on preclinical models. Some authors argued that MSCs are mobilized into the circulation with further migration and incorporation into the tumor microenvironment [153]. In that setting, MSC may contribute either to enhance tumor growth by decreasing apoptosis and promoting angiogenesis or to inhibit tumor growth in both in vitro and in vivo studies. Importantly, allogenic-derived MSC obtained from different sources and injected through different pathways for the treatment of broad clinical conditions, including graft-versus-host disease and cardiovascular and neurological diseases, was not associated with tumor development throughout a follow-up of 30 days to 6.8 years [153].

2.4. Clinical Studies. We have consulted the Clinical Trials web portal (clinicaltrials.gov, access in January 2020) with the keywords "mesenchymal stem cell" or "mesenchymal stromal cell" and "diabetes". We defined inclusion criteria as completed studies that have reported results on PubMed. These studies were mainly single-center prospective phase I/II clinical trials, which evaluated safety and tolerability and explored the therapeutic effects of MSCs on beta-cell regeneration and the impact on fasting plasma glucose (FBG), HbA1c, endogenous insulin, and C-peptide increment and the reduction of daily insulin requirement $\geq 50 \%$, which reached the efficacy level. A doseescalating $\left(0.3 \times 10^{6} / \mathrm{kg}, \quad 1.0 \times 10^{6} / \mathrm{kg}, \quad\right.$ or $\left.2.0 \times 10^{6} / \mathrm{kg}\right)$ randomized-controlled trial assessing one intravenous infusion of MPCs (rexlemestrocel-L) in DM2 individuals without DKD documented safety and efficacy of cell therapy [154]. In patients treated with the highest dose, there was a significant decrease in $\mathrm{HbAlc}$ at 8 weeks with $33 \%$ of patients achieving the clinical target $\mathrm{HbAlc}<7 \%$.

To note, there was only one multicentric study, which also included individuals with DKD [155]. In that randomized $(1: 1: 1)$, double-blind, sequential, dose-escalating $\left(150 \times 10^{6}\right.$ or $300 \times 10^{6}$, single intravenous dose), multicenter, and placebo-controlled trial, safety and efficacy of adult allogeneic BM-derived MPCs (MPCs, rexlemestrocel-L) were evaluated in type 2 diabetic individuals with DKD (eGFR 20$50 \mathrm{ml} / \mathrm{min} / 1.73 \mathrm{~m}^{2}$ ). In terms of safety, no patients exhibit treatment-related severe adverse events and only one patient developed antibody specific to the donor HLA (antibody specificity to donor antigen (class I) B40; mean fluorescence intensity 530) at week 4 that were undetectable at week 12 . The primary exploratory efficacy parameter comprised eGFR, so that the placebo-adjusted least square mean change in eGFR at week 12 was $4.4 \pm 2.2(\mathrm{p}=0.05)$ and $1.6 \pm 2.2$ $\mathrm{ml} / \mathrm{min} / 1.73 \mathrm{~m}^{2}(\mathrm{p}=0.47)$ for the $150 \times 10^{6}$ and $300 \times 10^{6}$ groups, respectively. Relative to placebo, there was a suggestion of stabilization of eGFR in the rexlemestrocel-L $150 \times 10^{6}$ group, most notably at the 12 -week primary endpoint. Importantly, when subgroup analyses were performed (GFR $\leq 30$ or $>30 \mathrm{ml} / \mathrm{min} / 1.73 \mathrm{~m}^{2}$ ), the subgroup with eGFR $>30$ $\mathrm{ml} / \mathrm{min} / 1.73 \mathrm{~m}^{2}$ treated with $150 \times 10^{6}$ cells manifested a lower decrease in eGFR when compared to the control group at 12 weeks $(p=0.04)$. In addition, there was a statistically significant decrease in the median IL- 6 values for the $300 \times 10^{6}$ group compared to placebo at week 12 , but not for other markers (HbAlc, TNF- $\alpha$, and C-reactive protein).

We observed a balanced distribution between allogeneicMSCs and autologous-MSC-based studies for both DM1 and DM2 individuals. MSCs have also shown beneficial effects on glycemic control when combined to hematopoietic stem cells (HSCs) or BM-MNCs. However, studies have still not been able to establish insulin-free status in this group of patients, even by differentiation of human AT-MSC into insulin-secreting MSCs (AT-ISC-MSC) [156-158]. That approach is based on growing MSCs with growth factors and serum with supplements, such as nicotinamide, activin A, exendin, pentagastrin, HGF, B-27, N2, and antibiotics for 4 days [158]. After that, these cells secrete Cpeptide and insulin in vitro and express genes responsible for insulin secretion (pax-6, pdx1, and isl-1).

Likewise, a nonmyeloablative low-intensity conditioning regimen combined to MSC therapy failed to demonstrate insulin independence [156-158]. The objective of the treatment is to stop autoimmune destruction of $\beta$-cells with high-dose immunosuppressive drugs. A similar approach was also attempted to reset the deleterious immunologic system with a reconstituted one originated from autologous hematopoietic stem cells [159]. The rationale is to preserve residual $\beta$-cell mass and facilitate endogenous mechanisms of $\beta$-cell regeneration. For example, a nonmyeloablative low-intensity conditioning regimen combined to autologous AT-IS-MSC and HSC was based on rabbit antithymocyte globulin, methylprednisolone, and bortezomib [158]. For allogeneic AT-ISC-MSC associated with HSC infusion, nonmyeloablative low-intensity conditioning included target specific irradiation to subdiaphragmatic lymph nodes, spleen, part of pelvic bones, and lumbar vertebrae before cell 
infusion [156]. In addition, anti-T cell antibody (rabbit antithymocyte globulin) and anti-B cell antibody (ABA) were administered intravenously to prevent rejection and facilitate grafting of transplanted cells. Of importance, no immunosuppressive medication was required posttransplant. To note, the outcomes in $\beta$-cell function from those studies should also be analyzed in light of the use of the immunosuppressive regimen per se.

MSC-based therapy was considered a safe procedure in all studies that verified the therapeutic potential of these cells. In a systematic review and meta-analysis of clinical trials that evaluated MSC safety in more than a thousand individuals diagnosed with other clinical conditions, a significant association between MSC infusion and fever was shown [160]. However, no other immediate event (acute infusion toxicity), organ system complications, infection, and long-term adverse events (death, malignancy) were documented.

In terms of efficacy, both autologous- $[157,158,161-$ 164] and allogeneic- [155, 156, 165-168] derived MSCs accomplished the major secondary endpoints, as effective in changing metabolic hallmarks of DM, such as Cpeptide synthesis and reducing exogenous insulin requirement, FBG, and HbAlc, as described in Tables 2 and 3, respectively. In the same way, allogeneic MSCs were effective as autologous MSCs in improving the final diastolic volume and left ventricular ejection fraction of patients with ischemic cardiomyopathy [169]. Notably, alloimmune reactions in those patients receiving allogeneic MSCs were very low (3.7\%). In renal transplant patients, the infusion of both autologous [170] and allogeneic [171] MSCs was considered safe and effective. These data suggest the possibility of developing a biobank of allogeneic MSCs for therapeutic purposes in several pathologies, since these cells lack the expression of class II MHC (Major Histocompatibility Complex) antigens and costimulatory molecules (CD80/B7.1 and CD86/B7.2) [39]. Noteworthily, the potential impact of donor-to-donor heterogeneity and the potential immunogenicity of allogeneic cells, depending on the culturing conditions and passages, the microenvironment, and the differentiation state, may alter the immunogenic phenotype, as recently reviewed [172].

Importantly, MSC differentiation, when exposed to a proinflammatory microenvironment, may result not only in upregulation of cell surface immunogenic molecules but also in a decrease in immunoregulatory or immunosuppressive molecule secretion, such as PGE2, as reviewed elsewhere [173]. On the other hand, when MSCs differentiate into chondrocytes, they may not impair the production of immunomodulatory molecules. Therefore, some strategies may overcome immunogenicity, such as using 3D cell culture conditions and gene therapy [173]. Notwithstanding that controversial data, the formation of donor-specific antibodies after allogeneic MSC injection occurs eventually is not sustained and does not adversely affect the benefits of cell therapy in clinical practice $[154,155,169,173,174]$. However, the implications of the development of alloantibodies still need to be assessed over longer time periods, alongside the tolerability and efficacy of single and repeated administration of allogeneic MSC before definite conclusions can be established. As discussed elsewhere, some key aspects to be taken into account include both preclinical (e.g., increased vigilance of cellular immunity in preclinical experiments, development of strategies to reduce alloantigen expression on allo-MSCs, determination of optimal tissue source of MSC, combination of allo-MSC therapies with immunomodulatory drugs, replacement of highly immunogenic cells with alternatives, and optimizing the route of administration and culture conditions) and clinical (e.g., prescreening for antidonor responses, tracking the development of humoral immune responses, performance of functionally analyses of adaptive antidonor responses, and systemic public reporting results) approaches [173].

In addition, those studies also raised important questions regarding the protocols related to MSC source and viability, the number of infusions, the number of infused cells, routes of administration, the ability of MSCs to migrate to the injury site, the potency of the MSCs in the context of disease, model, and outcome measure [57]. A key aspect suggests that efficacy may be curtailed by the sequestration within the lungs and early elimination, as discussed previously in Preclinical Studies: Small and Large Animals.

In a meta-analysis of UCB cell-, UCB-MSC-, BM-MSC-, and HSC-based therapies for both DM1 and DM2 individuals ( $n=22$ studies), it was documented that almost $60 \%$ of DM1 individuals ( $n=15$ studies, 300 patients, including 40 controls) became insulin-independent for a mean period of 16 months after HSC-MSC treatment (mean dose of $6.99 \pm$ $3.28 \times 10^{6}$ cells $/ \mathrm{kg} \mathrm{CD} 34^{+}$), as opposed to a negative response when these patients were treated with UCB cells (mean dose of $1.49 \times 10^{7}$ nucleated cells; mean number of $\mathrm{CD} 34^{+}$cells was $1.26 \times 10^{6}$ ) [175]. Likewise, UCB-MSC (range, $1.27 \times$ $10^{6} / \mathrm{kg}$ to $1.88 \times 10^{7} / \mathrm{kg}$; mean dose $2.6 \pm 1.2 \times 10^{7}$ ) therapy was superior to BM-MSC (mean dose of $2.75 \times 10^{6} / \mathrm{kg}$ ) therapy for DM1 individuals, when C-peptide levels were compared, but not in terms of decreasing HbAlc. For DM2 individuals ( $n=7$ studies, 224 patients, including 92 controls), no conclusive recommendation was defined, yet DMMNCs provided a better outcome when compared to UCBMSCs in improving C-peptide levels and decreasing HbAlc. The administration of cell therapy early after DM diagnosis was more effective than intervention at later stages (relative risk $=2.0$ ). To note, UCB cells $(n=3)$ and BMMNCs $(n=107)$ were injected intrapancreatically, whereas UCB-MSCs $(n=22)$ were injected intravenously. In addition, mean doses of BM-MNCs were $17.29 \times 10^{8}$ cells $/ \mathrm{kg}$ (mean number of $\mathrm{CD} 34^{+}$cells was $3.15 \times 10^{6}$ ) and mean doses of UCB cells were $5.29 \times 10^{9}$ (mean number of $\mathrm{CD} 34^{+}$was $2.88 \times 10^{6}$ ), whereas mean doses of UCB-MSCs were $1 \times$ $10^{6} / \mathrm{kg}$ (either intravenous or intrapancreatic). Whether the number of injected cells and the route of injection (intrapancreatic versus intravenous) are associated with better outcomes, further studies are warranted to reach a definitive conclusion. Importantly, the patient clinical condition may also play a role in cell therapy, as diabetic ketoacidosis may impair its efficacy.

In another recent meta-analysis including DM2 individuals ( $n=6$ studies, 206 patients), treatment with autologous 


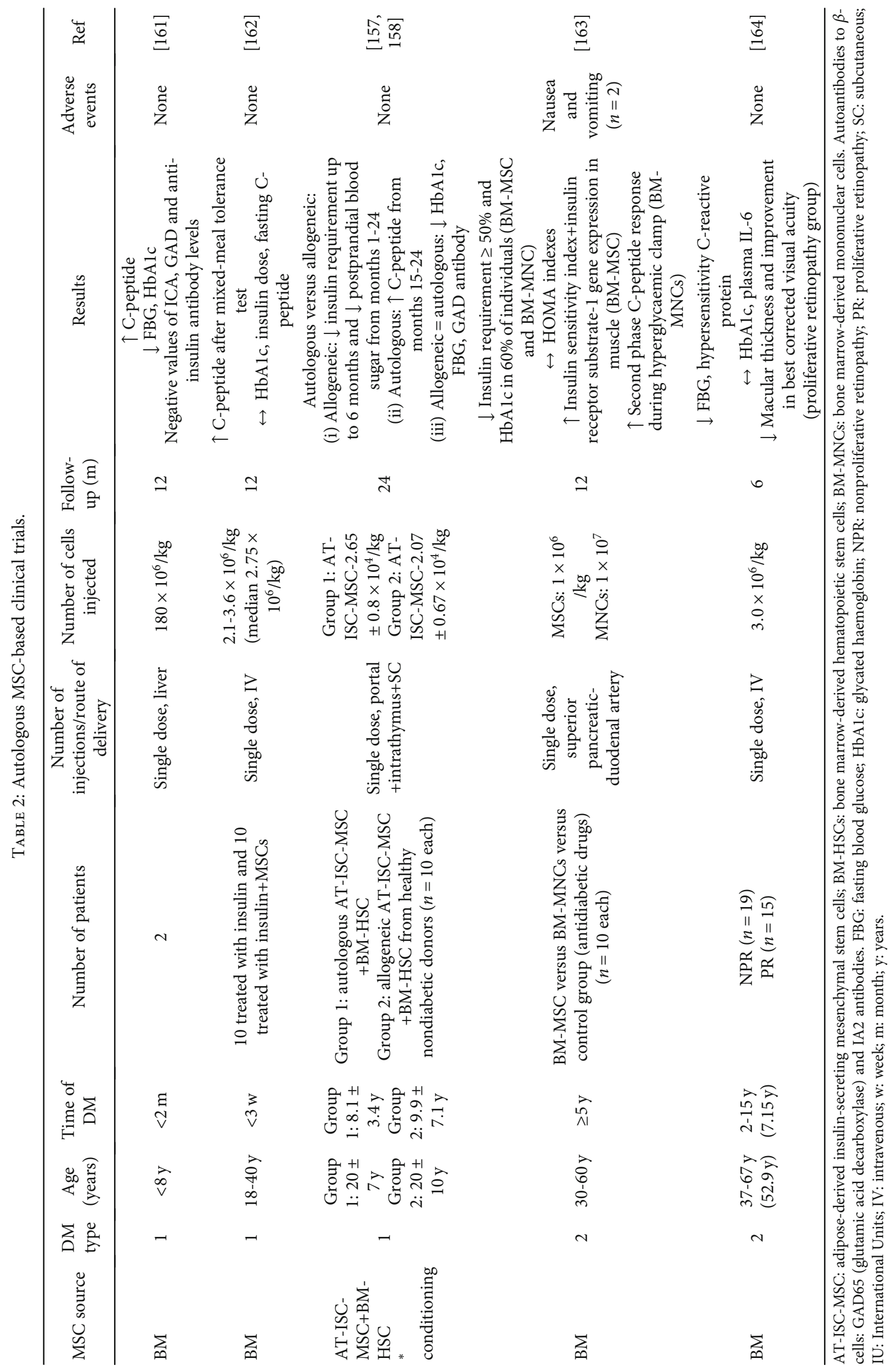




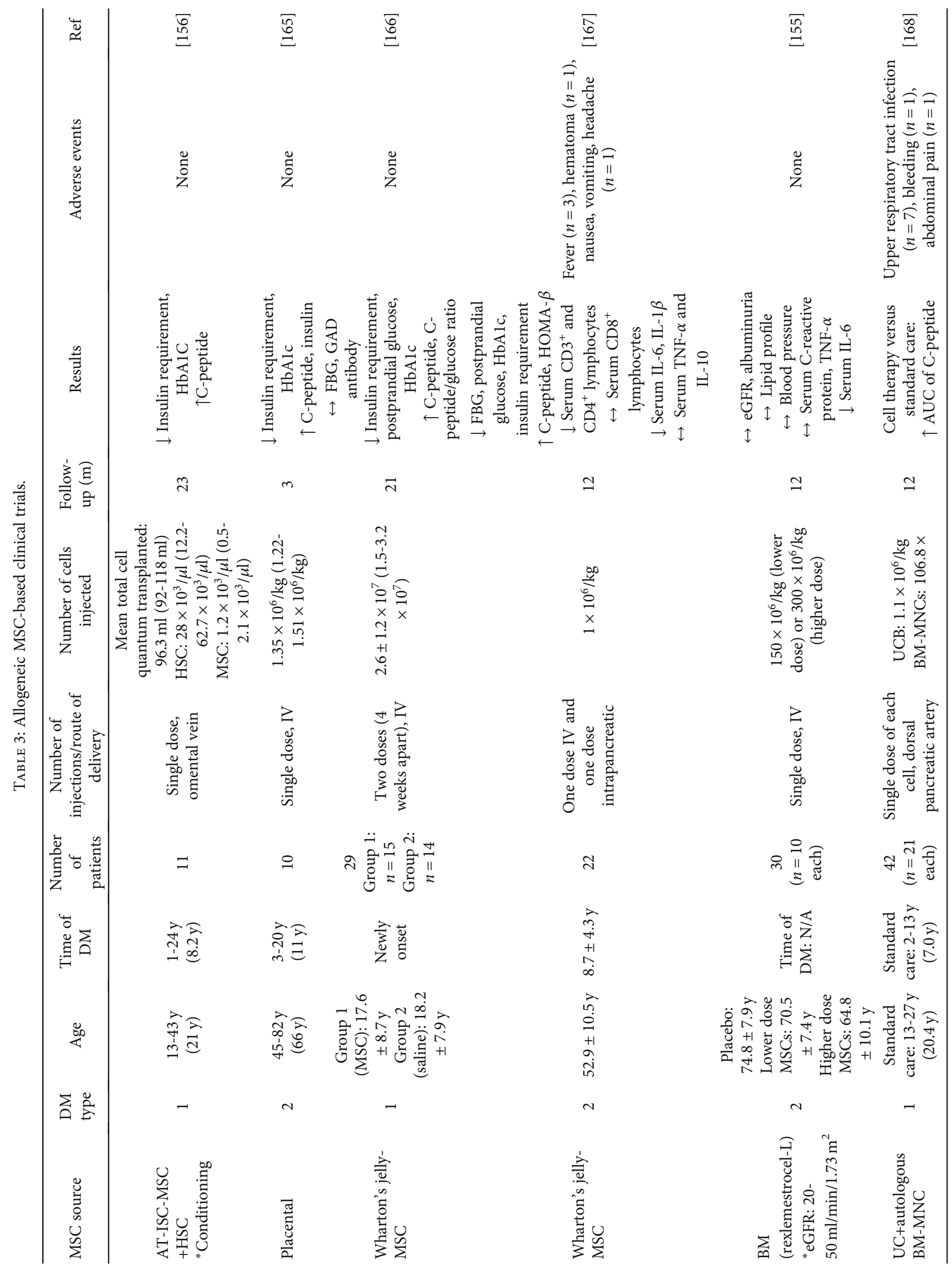




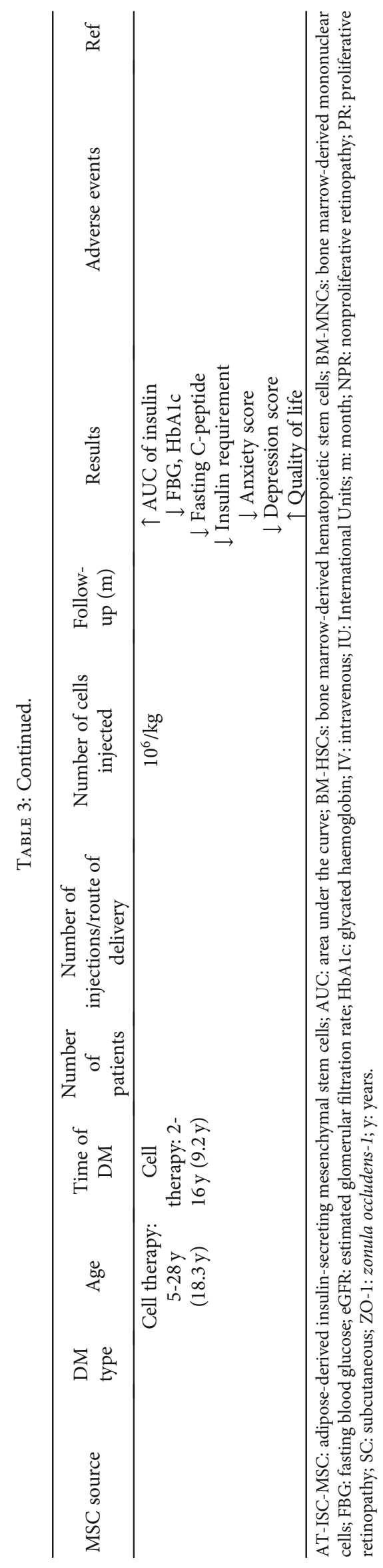




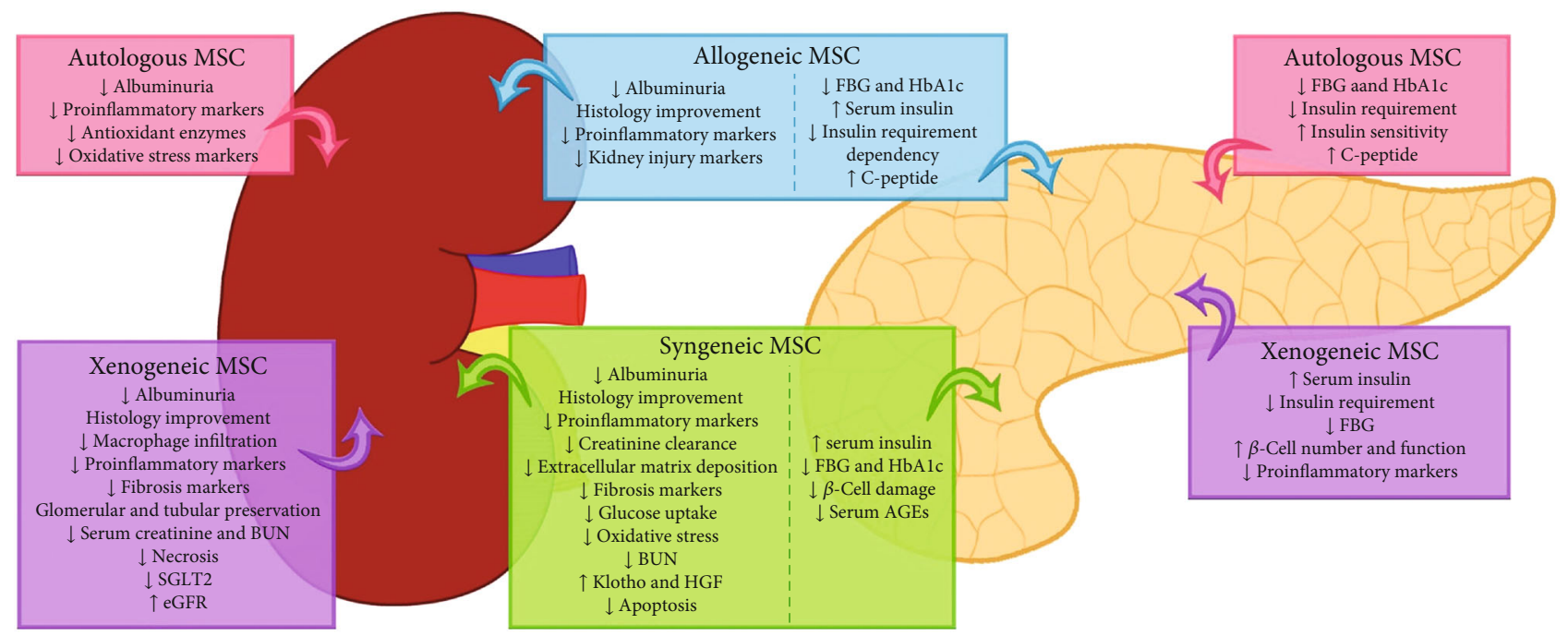

FIgURE 1: Main findings of preclinical and clinical studies evaluating MSC efficacy.

BM-MNCs (dose ranged from $382.6 \pm 10^{7}$ to $2.8 \pm 1.9 \times 10^{9}$ cells) was effective in reducing HbAlc by $1.18 \%$ and insulin requirement during a follow-up of 12 months [176].

\section{Future Directions}

Strategies such as gene modification, optimization of culture conditions, and pretreatment conditioning may lead to an improvement in MSC functionality and a decrease in heterogeneity. These strategies comprise hypoxia culture, pharmacological agents, trophic factors/cytokines, small molecules, physical factors/materials, and gene modification, which may all contribute to better tissue repair and regeneration mediated by MSCs [177].

MSCs are generally grown in an environment with $21 \%$ oxygen tension. However, physiologically, MSCs are found in an environment with a much lower oxygen tension ( $1 \%$ to $7 \%$ ). Thus, the cultivation or preconditioning of MSCs in a hypoxia environment with $2 \%$ or $5 \%$ oxygen allows these cells to remain multipotent and have greater proliferative and migratory capacity, in addition to lower senescence rates $[178,179]$. Importantly, MSCs preconditioned by hypoxia do not differentiate into fibroblasts associated with tumors in vitro and do not induce tumors in vivo [178].

In order to reduce the heterogeneity of the MSC profile, which is defined by the different isolation and culture protocols, the preconditioning of these cells with proinflammatory factors has been the focus of investigation. Thus, the preconditioning of MSCs through stimulation with IFN- $\gamma$, TNF- $\alpha$, PGE2, and NO oxide mitigated the heterogeneous behavior of MSCs on Tlymphocyte proliferation assays and on late type hypersensitivity response [180].

MSCs can also be tested as carriers of genes or genetic modifications. Due to their ability to migrate to injury sites, MSCs represent a robust platform for delivery of genes associated with regeneration and repair of renal tissue, functioning as a "Trojan Horse" [181]. Thus, several genes associated with trophic factors may be used for these purposes, such as
HGF and klotho, since they are renoprotective, as reviewed elsewhere [16].

In addition, genetic modifications of MSCs, which are also very promising in the context of $\mathrm{DKD}$, include the overexpression of erythropoietin, CXCR4, CTLA4Ig, and IL$10 /$ selectin, as well as the transfection of minicircles containing biological drugs, such as etanercept, which is a TNF- $\alpha$ blocker [182], and transfection of nanoparticles containing iron oxide, polymers, and plasmids [183].

Despite MSC-based preconditioning treatment that has not been associated with harmful effects, further studies are required to verify its effectiveness in maintaining MSC properties.

To advance MSC-based therapy, production of a large amount of these cells is challenging. Automated hollowfiber bioreactors were validated to the development of large-scale manufacturing MSCs, providing cells with preserved characteristics and functionality when compared to the manual multilayer flask method [184, 185]. That approach may be cost- and time-saving at the end of the day.

MSC-derived secretome is a cell-free alternative for treating DM1 and DM2 individuals, which can bypass some issues related to autologous and allogeneic MSCs [186]. Some advantages include the absence of antigenic factors, timesaving obtainment, and the adaptation of MSC to produce preestablished secretome components, designed to target specific pathologies, even separating vesicles from soluble proteins and adapting cell product to each disease scenario.

\section{Conclusions}

Laboratory research set the basis for establishing further translation research including preclinical development and proof of concept in model systems. Thus, animal models indicate that syngeneic, autologous, allogeneic, and xenogeneic MSCs are effective for treating metabolic dysfunction in the DM setting and for halting the progression of DKD. MSCs demonstrated efficacy in controlling several biological processes, such as apoptosis, autophagy, fibrosis, 
inflammation, and oxidative stress, as well as in ameliorating renal functional and structural parameters.

BM-MSCs have been applied as the most valuable source of autologous cell transplants for diabetic complications in animals and humans. Despite differential gene expression, expanded MSCs from DM1 donors are phenotypically and functionally similar to healthy control MSCs with regard to their immunomodulatory, migratory potential, multilineage differentiation, and secretion of growth factors. MSCs from DM2 donors exhibit dysfunctional properties, such as senescence, angiogenesis impairment, higher rates of apoptosis, and lower clonogenic potential. Therefore, hyperglycemia may cause abnormalities in intrinsic BM-MSC, which might lose sufficient therapeutic effects in DM2 individuals. Of importance, DM2 donors are usually older and exhibit hyperglycemia for a longer duration, so that aging may play an additional role in MSC dysfunction. Therefore, preconditioning strategies can be used to recover the characteristics and functions of MSCs of diabetic patients before infusion and, thus, improve their performance in autologous therapies in terms of tissue repair and regeneration.

Together, the bench to bedside pathway has been constructed in the last decade. Laboratory research set the basis for establishing further translation research including preclinical development and proof of concept in model systems [187]. In Figure 1, we summarized the main findings of preclinical and clinical studies. Accordingly, phase I clinical trials (safety studies in humans) have substantiated the safe profile of MSC-based therapy, and phase II clinical trials (proof of concept in trial participants) still need to answer important questions. Therefore, well-designed large-scale randomized studies considering the stem cell type, cell number, and infusion method in DM patients are further needed in order to move to phase III clinical trials (largescale trials to show significant efficacy). In addition, that pathway should include interactions with regulatory agencies and the protocols involved in the Investigational New Drug (IND) application development.

Clinical trials using MSC-based therapy indicate that infusion of autologous or allogeneic MSCs is generally well tolerated. Phase II clinical trials including a longer period of observation will support the efficacy of MSCs. However, the use of these cells to treat diabetic individuals with DKD awaits clinical validation. In conclusion, MSC-based preclinical and phase I/II clinical data encourage the design of future large-scale controlled clinical trials that evaluate DKD response to MSC therapy, while rigorous reporting of safety and efficacy is still needed.

\section{Abbreviations}

AGEs:

AMDCC:

AT-MSC:

AT-IS-MSC:

BM-MSC:

$\mathrm{BTBR}^{o b / o b}$ mice:
Advanced glycation end products Animal Models of Diabetic Complications Consortium

Adipose tissue-derived MSCs AT-insulin-secreting-derived MSCs Bone marrow-derived MSCs Black and tan, obese, and tufted $o b / o b$ (leptin deficient) mice
CFU-f:

CKD:

CV:

CXCL:

CXCR:

DKD:

DM:

DPP-4 inhibitors:

DRD:

ESKD:

EXOs:

FBG:

GBM:

eGFR:

GLP1-RA:

GMCs:

GMP:

HbA1c:

HGF:

HSCs:

IDO:

IFN- $\gamma$ :

IGF-1:

IL:

IND:

iNOS:

ISC:

ISCT:

LPS:

MCP-1:

MHC:

MIP:

MSCs:

NO:

NOD:

PDGF:

PGE2:

PKC:

RAAS:

Sca-1:

SDF-1:

SGLT(i):

STZ:

TGF- $\beta 1$ :

TLR:

TNF- $\alpha$ :

TEC:

UAE:

UCB-MSCs:

UTMD:

VEGF-A:
Colony Forming Unit-fibroblast

Chronic kidney disease

Cardiovascular

Chemokine (C-X-C motif) ligand

$\mathrm{C}-\mathrm{X}-\mathrm{C}$ chemokine receptor

Diabetic kidney disease

Diabetes mellitus

Dipeptidyl peptidase- 4 inhibitors

Diabetic renal disease

End-stage kidney renal disease

Exosomes

Fasting plasma glucose

Glomerular basement membrane

Estimated glomerular filtration rate

Glucagon-like peptide 1 receptor agonists

Glomerular mesangial cells

Good Manufacturing Practice

Glycated haemoglobin

Hepatocyte growth factor

Hematopoietic stem cells

Indoleamine 2,3-dioxygenase

Interferon- $\gamma$

Insulin growth factor

Interleukin

Investigational New Drug

Inducible nitric oxide synthase

Insulin-secreting cells

International Society for Cell Therapy

Lipopolysaccharide

Monocyte chemoattractant protein-1

Major complex of histocompatibility

Macrophage inflammatory protein

Mesenchymal stem/stromal cells

Nitric oxide

Nonobese diabetic mouse

Platelet-derived growth factor

Prostaglandin E2

Protein kinase $\mathrm{C}$

Renin-angiotensin-aldosterone system

Stem cell antigen-1

Stromal-derived factor-1

Sodium-glucose cotransporter

(inhibitors)

Streptozotocin

Transforming growth factor- $\beta 1$

Toll-like receptors

Tumor necrosis factor- $\alpha$

Tubular epithelial cells

Urinary albumin excretion

Umbilical cord blood-derived MSCs

Ultrasound-targeted microbubble

destruction

Vascular endothelial growth factor A.

\section{Data Availability}

Our manuscript is based on a review of articles that have been already published on PubMed. 


\section{Conflicts of Interest}

The authors declare that they have no conflict of interest.

\section{Acknowledgments}

This work was supported by grants from FAPESP (Fundação de Amparo à Pesquisa do Estado de São Paulo/São Paulo Research Foundation (2017/18072-9), CNPq (Conselho Nacional de Desenvolvimento Científico e Tecnológico/National Counsel of Technological and Scientific Development; \# 456959/2013-0 and 423320/2016-5), EFSD (European Foundation for the Study of Diabetes) to Érika B Rangel, FAPESP to Christian Sávio-Silva (2017/18072-9), FAPESP to Poliana E Soinski-Sousa (2018/24562-1), and FAPESP to Maria Theresa A Balby-Rocha (2019/12636-3).

\section{References}

[1] P. Saeedi, I. Petersohn, P. Salpea et al., "Global and regional diabetes prevalence estimates for 2019 and projections for 2030 and 2045: results from the International Diabetes Federation Diabetes Atlas, 9th edition," Diabetes Research and Clinical Practice, vol. 157, p. 107843, 2019.

[2] IDF Diabetes Atlas Group, "Update of mortality attributable to diabetes for the IDF Diabetes Atlas: estimates for the year 2013," Diabetes Research and Clinical Practice, vol. 109, no. 3, pp. 461-465, 2015.

[3] R. Z. Alicic, M. T. Rooney, and K. R. Tuttle, "Diabetic kidney disease: challenges, progress, and possibilities," Clinical Journal of the American Society of Nephrology, vol. 12, no. 12, pp. 2032-2045, 2017.

[4] R. Saran, B. Robinson, K. C. Abbott et al., "US renal data system 2016 annual data report: epidemiology of kidney disease in the United States," American Journal of Kidney Diseases, vol. 69, no. 3, pp. A7-A8, 2017.

[5] E. Porrini, P. Ruggenenti, C. E. Mogensen et al., "Non-proteinuric pathways in loss of renal function in patients with type 2 diabetes," The Lancet Diabetes and Endocrinology, vol. 3, no. 5, pp. 382-391, 2015.

[6] M. Haneda, K. Utsunomiya, D. Koya et al., "A new classification of diabetic nephropathy 2014: a report from Joint Committee on Diabetic Nephropathy," Journal of Diabetes Investigation, vol. 6, no. 2, pp. 242-246, 2015.

[7] T. P. Griffin, W. P. Martin, N. Islam, T. O’Brien, and M. D. Griffin, "The promise of mesenchymal stem cell therapy for diabetic kidney disease," Current Diabetes Reports, vol. 16, no. 5, 2016.

[8] S. Toth-Manikowski and M. G. Atta, "Diabetic kidney disease: pathophysiology and therapeutic targets," Journal of Diabetes Research, vol. 2015, Article ID 697010, 16 pages, 2015.

[9] M. E. Molitch, A. I. Adler, A. Flyvbjerg et al., "Diabetic kidney disease: a clinical update from kidney disease: improving global outcomes," Kidney International, vol. 87, no. 1, pp. 20-30, 2015.

[10] S. S. Roscioni, H. J. Lambers Heerspink, and D. de Zeeuw, "The effect of RAAS blockade on the progression of diabetic nephropathy," Nature Reviews Nephrology, vol. 10, no. 2, pp. 77-87, 2014.
[11] S. E. Ivory, D. K. Packham, A. T. Reutens et al., "Residual proteinuria and eGFR predict progression of renal impairment within 2 years in type 2 diabetic patients with nephropathy who are receiving optimal treatment with angiotensin receptor blockers," Nephrology, vol. 18, no. 7, pp. 516-524, 2013.

[12] P. Ruggenenti, E. Perticucci, P. Cravedi et al., "Role of remission clinics in the longitudinal treatment of CKD," Journal of the American Society of Nephrology, vol. 19, no. 6, pp. 12131224, 2008.

[13] L. F. Fried, N. Emanuele, J. H. Zhang et al., "Combined angiotensin inhibition for the treatment of diabetic nephropathy," The New England Journal of Medicine, vol. 369, no. 20, pp. 1892-1903, 2013.

[14] T. A. Zelniker, S. D. Wiviott, I. Raz et al., "Comparison of the effects of glucagon-like peptide receptor agonists and sodium-glucose cotransporter 2 inhibitors for prevention of major adverse cardiovascular and renal outcomes in type 2 diabetes mellitus," Circulation, vol. 139, no. 17, pp. 20222031, 2019.

[15] A. Y. Kluger, K. M. Tecson, A. Y. Lee et al., "Class effects of SGLT2 inhibitors on cardiorenal outcomes," Cardiovascular Diabetology, vol. 18, no. 1, p. 99, 2019.

[16] J. Paulini, E. Higuti, R. M. C. Bastos, S. A. Gomes, and É. B. Rangel, "Mesenchymal stem cells as therapeutic candidates for halting the progression of diabetic nephropathy," Stem Cells International, vol. 2016, Article ID 9521629, 16 pages, 2016.

[17] A. J. Friedenstein, R. K. Chailakhjan, and K. S. Lalykina, "The development of fibroblast colonies in monolayer cultures of guinea-pig bone marrow and spleen cells," Cell and Tissue Kinetics, vol. 3, pp. 393-403, 1970.

[18] A. R. Williams and J. M. Hare, "Mesenchymal stem cells: biology, pathophysiology, translational findings, and therapeutic implications for cardiac disease," Circulation Research, vol. 109, pp. 923-940, 2011.

[19] A. I. Caplan, "Molecular and cellular differentiation of muscle, cartilage, and bone in the developing limb," Progress in Clinical and Biological Research, vol. 217B, pp. 307-318, 1986.

[20] M. A. Eglitis and E. Mezey, "Hematopoietic cells differentiate into both microglia and macroglia in the brains of adult mice," Proceedings of the National Academy of Sciences of the United States of America, vol. 94, pp. 4080-4085, 1997.

[21] G. C. Kopen, D. J. Prockop, and D. G. Phinney, "Marrow stromal cells migrate throughout forebrain and cerebellum, and they differentiate into astrocytes after injection into neonatal mouse brains," Proceedings of the National Academy of Sciences of the United States of America, vol. 96, pp. 1071110716, 1999.

[22] Y. Sato, H. Araki, J. Kato et al., "Human mesenchymal stem cells xenografted directly to rat liver are differentiated into human hepatocytes without fusion," Blood, vol. 106, pp. 756-763, 2005.

[23] K. S. Choi, J.-S. Shin, J.-J. Lee, Y. S. Kim, S.-B. Kim, and C.W. Kim, "In vitro trans-differentiation of rat mesenchymal cells into insulin-producing cells by rat pancreatic extract," Biochemical and Biophysical Research Communications, vol. 330, pp. 1299-1305, 2005.

[24] C. Toma, M. F. Pittenger, K. S. Cahill, B. J. Byrne, and P. D. Kessler, "Human mesenchymal stem cells differentiate to a cardiomyocyte phenotype in the adult murine heart," Circulation, vol. 105, pp. 93-98, 2002. 
[25] T. Imasawa, Y. Utsunomiya, T. Kawamura et al., "The potential of bone marrow-derived cells to differentiate to glomerular mesangial cells," Journal of the American Society of Nephrology, vol. 12, pp. 1401-1409, 2001.

[26] T. Yokoo, T. Ohashi, J. S. Shen et al., "Human mesenchymal stem cells in rodent whole-embryo culture are reprogrammed to contribute to kidney tissues," Proceedings of the National Academy of Sciences of the United States of America, vol. 102, pp. 3296-3300, 2005.

[27] J. Driscoll and T. Patel, "The mesenchymal stem cell secretome as an acellular regenerative therapy for liver disease," Journal of Gastroenterology, vol. 54, pp. 763-773, 2019.

[28] V. B. R. Konala, M. K. Mamidi, R. Bhonde, A. K. Das, R. Pochampally, and R. Pal, "The current landscape of the mesenchymal stromal cell secretome: a new paradigm for cell-free regeneration," Cytotherapy, vol. 18, no. 1, pp. 13-24, 2016.

[29] J. L. Spees, R. H. Lee, and C. A. Gregory, "Mechanisms of mesenchymal stem/stromal cell function," Stem Cell Research \& Therapy, vol. 7, no. 1, p. 125, 2016.

[30] R. A. Haraszti, M.-C. Didiot, E. Sapp et al., "High-resolution proteomic and lipidomic analysis of exosomes and microvesicles from different cell sources," Journal of Extracellular Vesicles, vol. 5, p. 32570, 2016.

[31] M. L. da Silva, P. C. Chagastelles, and N. B. Nardi, "Mesenchymal stem cells reside in virtually all post-natal organs and tissues," Journal of Cell Science, vol. 119, pp. 22042213, 2006.

[32] S. V. Murphy and A. Atala, "Amniotic fluid and placental membranes: unexpected sources of highly multipotent cells," Seminars in Reproductive Medicine, vol. 31, pp. 62-68, 2013.

[33] D. A. De Ugarte, K. Morizono, A. Elbarbary et al., "Comparison of multi-lineage cells from human adipose tissue and bone marrow," Cells, Tissues, Organs, vol. 174, no. 3, pp. 101-109, 2003.

[34] B. A. Bunnell, M. Flaat, C. Gagliardi, B. Patel, and C. Ripoll, "Adipose-derived stem cells: isolation, expansion and differentiation," Methods, vol. 45, pp. 115-120, 2008.

[35] N. Beeravolu, C. McKee, A. Alamri et al., "Isolation and characterization of mesenchymal stromal cells from human umbilical cord and fetal placenta," Journal of Visualized Experiments, vol. 122, no. article e55224, 2017.

[36] Y.-J. Chang, D. T.-b. Shih, C.-P. Tseng, T.-B. Hsieh, D.C. Lee, and S.-M. Hwang, "Disparate mesenchyme-lineage tendencies in mesenchymal stem cells from human bone marrow and umbilical cord blood," Stem Cells, vol. 24, pp. 679-685, 2006.

[37] W. Tsuji, J. P. Rubin, and K. G. Marra, "Adipose-derived stem cells: implications in tissue regeneration," World Journal of Stem Cells, vol. 6, pp. 312-321, 2014.

[38] J. Galipeau, M. Krampera, J. Barrett et al., "International Society for Cellular Therapy perspective on immune functional assays for mesenchymal stromal cells as potency release criterion for advanced phase clinical trials," Cytotherapy, vol. 18, pp. 151-159, 2016.

[39] Y.-S. Chen, Y.-A. Chen, P.-H. Tsai, C.-P. Chen, S.-W. Shaw, and Y. Hsuan, "Mesenchymal stem cell: considerations for manufacturing and clinical trials on cell therapy product," International Journal of Stem cell Research \& Therapy, vol. 3, p. 29, 2016.

[40] S. Viswanathan, Y. Shi, J. Galipeau et al., "Mesenchymal stem versus stromal cells: International Society for Cell \& Gene
Therapy (ISCT(R)) Mesenchymal Stromal Cell committee position statement on nomenclature," Cytotherapy, vol. 21, pp. 1019-1024, 2019.

[41] R. S. Waterman, S. L. Tomchuck, S. L. Henkle, and A. M. Betancourt, "A new mesenchymal stem cell (MSC) paradigm: polarization into a pro-inflammatory MSC1 or an immunosuppressive MSC2 phenotype," PLoS One, vol. 5, article e10088, 2010.

[42] R. Chinnadurai, D. Rajan, M. Qayed et al., "Potency analysis of mesenchymal stromal cells using a combinatorial assay matrix approach," Cell Reports, vol. 22, pp. 2504-2517, 2018.

[43] O. S. Kim, Y. S. Kim, D. S. Jang, N. H. Yoo, and J. S. Kim, "Cytoprotection against hydrogen peroxide-induced cell death in cultured mouse mesangial cells by erigeroflavanone, a novel compound from the flowers of Erigeron annuus," Chemico-Biological Interactions, vol. 180, pp. 414-420, 2009.

[44] X. An, G. Liao, Y. Chen et al., "Intervention for early diabetic nephropathy by mesenchymal stem cells in a preclinical nonhuman primate model," Stem Cell Research \& Therapy, vol. 10, p. 363, 2019.

[45] J. Sun, F. Zhao, W. Zhang, J. Lv, J. Lv, and A. Yin, "BMSCs and miR-124a ameliorated diabetic nephropathy via inhibiting notch signalling pathway," Journal of Cellular and Molecular Medicine, vol. 22, pp. 4840-4855, 2018.

[46] J. Jin, Y. Shi, J. Gong et al., "Exosome secreted from adiposederived stem cells attenuates diabetic nephropathy by promoting autophagy flux and inhibiting apoptosis in podocyte," Stem Cell Research \& Therapy, vol. 10, p. 95, 2019.

[47] S. Lv, G. Liu, A. Sun et al., "Mesenchymal stem cells ameliorate diabetic glomerular fibrosis in vivo and in vitro by inhibiting TGF- $\beta$ signalling via secretion of bone morphogenetic protein 7," Diabetes \& Vascular Disease Research, vol. 11, no. 4, pp. 251-261, 2014.

[48] Y. Bai, J. Wang, Z. He, M. Yang, L. Li, and H. Jiang, "Mesenchymal stem cells reverse diabetic nephropathy disease via lipoxin A4 by targeting transforming growth factor $\beta$ (TGF$\beta) /$ smad pathway and pro-inflammatory cytokines," Medical Science Monitor, vol. 25, pp. 3069-3076, 2019.

[49] W. Ni, Y. Fang, L. Xie et al., “Adipose-derived mesenchymal stem cells transplantation alleviates renal injury in streptozotocin-induced diabetic nephropathy," The Journal of Histochemistry and Cytochemistry, vol. 63, no. 11, pp. 842-853, 2015.

[50] K. Nagaishi, Y. Mizue, T. Chikenji et al., "Mesenchymal stem cell therapy ameliorates diabetic nephropathy via the paracrine effect of renal trophic factors including exosomes," Scientific Reports, vol. 6, no. 1, p. 34842, 2016.

[51] L. Wang, L. Qing, H. Liu et al., "Mesenchymal stromal cells ameliorate oxidative stress-induced islet endothelium apoptosis and functional impairment via Wnt4- $\beta$-catenin signaling," Stem Cell Research \& Therapy, vol. 8, no. 1, p. 188, 2017.

[52] Y. Li, J. Liu, G. Liao et al., "Early intervention with mesenchymal stem cells prevents nephropathy in diabetic rats by ameliorating the inflammatory microenvironment," International Journal of Molecular Medicine, vol. 41, no. 5, pp. 2629-2639, 2018.

[53] S. E. Lee, J. E. Jang, H. S. Kim et al., "Mesenchymal stem cells prevent the progression of diabetic nephropathy by improving mitochondrial function in tubular epithelial cells," Experimental \& Molecular Medicine, vol. 51, no. 7, p. 77, 2019. 
[54] H. Vashistha, L. Marrero, K. Reiss et al., "Aging phenotype(s) in kidneys of diabetic mice are p66ShcA dependent," American Journal of Physiology. Renal Physiology, vol. 315, no. 6, pp. F1833-F1842, 2018.

[55] C. Sávio-Silva, P. E. Soinski-Sousa, M. T. A. Balby-Rocha, Á. de Oliveira Lira, and É. B. Rangel, "Mesenchymal stem cell therapy in acute kidney injury (AKI): review and perspectives," Revista da Associação Médica Brasileira, vol. 66, Supplement 1, pp. s45-s54, 2020.

[56] Y. Wang, J. He, X. Pei, and W. Zhao, "Systematic review and meta-analysis of mesenchymal stem/stromal cells therapy for impaired renal function in small animal models," Nephrology, vol. 18, pp. 201-208, 2013.

[57] A. M. Dimarino, A. I. Caplan, and T. L. Bonfield, "Mesenchymal stem cells in tissue repair," Frontiers in Immunology, vol. 4, p. 201, 2013.

[58] A. Keating, "Mesenchymal stromal cells: new directions," Cell Stem Cell, vol. 10, pp. 709-716, 2012.

[59] M. E. Bernardo and W. E. Fibbe, "Mesenchymal stromal cells: sensors and switchers of inflammation," Cell Stem Cell, vol. 13, pp. 392-402, 2013.

[60] F. Casiraghi, N. Perico, M. Cortinovis, and G. Remuzzi, "Mesenchymal stromal cells in renal transplantation: opportunities and challenges," Nature Reviews. Nephrology, vol. 12, no. 4, pp. 241-253, 2016.

[61] M. E. J. Reinders, J. W. de Fijter, H. Roelofs et al., “Autologous bone marrow-derived mesenchymal stromal cells for the treatment of allograft rejection after renal transplantation: results of a phase I study," Stem Cells Translational Medicine, vol. 2, no. 2, pp. 107-111, 2013.

[62] N. Perico, F. Casiraghi, E. Gotti et al., "Mesenchymal stromal cells and kidney transplantation: pretransplant infusion protects from graft dysfunction while fostering immunoregulation," Transplant International, vol. 26, no. 9, pp. 867-878, 2013.

[63] F. Casiraghi, N. Perico, E. Gotti et al., "Kidney transplant tolerance associated with remote autologous mesenchymal stromal cell administration," Stem Cells Translational Medicine, vol. 9, no. 4, pp. 427-432, 2020.

[64] S. Villanueva, E. Ewertz, F. Carrión et al., "Mesenchymal stem cell injection ameliorates chronic renal failure in a rat model," Clinical Science (London, England), vol. 121, no. 11, pp. 489499, 2011.

[65] S. Villanueva, J. . E. Carreño, L. Salazar et al., "Human mesenchymal stem cells derived from adipose tissue reduce functional and tissue damage in a rat model of chronic renal failure," Clinical Science (London, England), vol. 125, no. 4, pp. 199-210, 2013.

[66] M. B. Herrera, B. Bussolati, S. Bruno, V. Fonsato, G. M. Romanazzi, and G. Camussi, "Mesenchymal stem cells contribute to the renal repair of acute tubular epithelial injury," International Journal of Molecular Medicine, vol. 14, no. 6, pp. 1035-1041, 2004.

[67] H. Qian, H. Yang, W. Xu et al., "Bone marrow mesenchymal stem cells ameliorate rat acute renal failure by differentiation into renal tubular epithelial-like cells," International Journal of Molecular Medicine, vol. 22, no. 3, pp. 325-332, 2008.

[68] E. Ronconi, C. Sagrinati, M. L. Angelotti et al., "Regeneration of glomerular podocytes by human renal progenitors," Journal of the American Society of Nephrology, vol. 20, no. 2, pp. 322-332, 2009.
[69] B. Mazzinghi, E. Ronconi, E. Lazzeri et al., "Essential but differential role for CXCR4 and CXCR7 in the therapeutic homing of human renal progenitor cells," The Journal of Experimental Medicine, vol. 205, no. 2, pp. 479-490, 2008.

[70] U. M. Fischer, M. T. Harting, F. Jimenez et al., "Pulmonary passage is a major obstacle for intravenous stem cell delivery: the pulmonary first-pass effect," Stem Cells and Development, vol. 18, no. 5, pp. 683-692, 2009.

[71] S. Schrepfer, T. Deuse, H. Reichenspurner, M. P. Fischbein, R. C. Robbins, and M. P. Pelletier, "Stem cell transplantation: the lung barrier," Transplantation Proceedings, vol. 39, no. 2, pp. 573-576, 2007.

[72] Q. Feng, P. K. H. Chow, F. Frassoni et al., "Nonhuman primate allogeneic hematopoietic stem cell transplantation by intraosseus vs intravenous injection: engraftment, donor cell distribution, and mechanistic basis," Experimental Hematology, vol. 36, no. 11, pp. 1556-1566, 2008.

[73] S. M. Devine, C. Cobbs, M. Jennings, A. Bartholomew, and R. Hoffman, "Mesenchymal stem cells distribute to a wide range of tissues following systemic infusion into nonhuman primates," Blood, vol. 101, no. 8, pp. 2999-3001, 2003.

[74] M. Morigi, M. Introna, B. Imberti et al., "Human bone marrow mesenchymal stem cells accelerate recovery of acute renal injury and prolong survival in mice," Stem Cells, vol. 26, no. 8, pp. 2075-2082, 2008.

[75] F. Tögel, Z. Hu, K. Weiss, J. Isaac, C. Lange, and C. Westenfelder, "Administered mesenchymal stem cells protect against ischemic acute renal failure through differentiation-independent mechanisms," American Journal of Physiology. Renal Physiology, vol. 289, no. 1, pp. F31-F42, 2005.

[76] S. Sedrakyan, S. Da Sacco, A. Milanesi et al., "Injection of amniotic fluid stem cells delays progression of renal fibrosis," Journal of the American Society of Nephrology, vol. 23, pp. 661-673, 2012.

[77] U. Kunter, S. Rong, Z. Djuric et al., "Transplanted mesenchymal stem cells accelerate glomerular healing in experimental glomerulonephritis," Journal of the American Society of Nephrology, vol. 17, no. 8, pp. 2202-2212, 2006.

[78] U. Kunter, S. Rong, P. Boor et al., "Mesenchymal stem cells prevent progressive experimental renal failure but maldifferentiate into glomerular adipocytes," Journal of the American Society of Nephrology, vol. 18, no. 6, pp. 1754-1764, 2007.

[79] S. Gupta, C. Verfaillie, D. Chmielewski et al., "Isolation and characterization of kidney-derived stem cells," Journal of the American Society of Nephrology, vol. 17, no. 11, pp. 3028-3040, 2006.

[80] E. B. Rangel, S. A. Gomes, R. A. Dulce et al., "C-kit(+) cells isolated from developing kidneys are a novel population of stem cells with regenerative potential," Stem Cells, vol. 31, no. 8, pp. 1644-1656, 2013.

[81] E. B. Rangel, S. A. Gomes, R. Kanashiro-Takeuchi et al., "Kidney-derived c-kit(+) progenitor/stem cells contribute to podocyte recovery in a model of acute proteinuria," Scientific Reports, vol. 8, p. 14723, 2018.

[82] E. B. Rangel, S. A. Gomes, R. Kanashiro-Takeuchi, and J. M. Hare, "Progenitor/stem cell delivery by suprarenal aorta route in acute kidney injury," Cell Transplantation, vol. 28, no. 11, pp. 1390-1403, 2019.

[83] F. Tögel, Y. Yang, P. Zhang, Z. Hu, and C. Westenfelder, "Bioluminescence imaging to monitor the in vivo 
distribution of administered mesenchymal stem cells in acute kidney injury," American Journal of Physiology. Renal Physiology, vol. 295, no. 1, pp. F315-F321, 2008.

[84] L. Behr, M. Hekmati, G. Fromont et al., "Intra renal arterial injection of autologous mesenchymal stem cells in an ovine model in the postischemic kidney," Nephron. Physiology, vol. 107, pp. 65-76, 2007.

[85] S. Kitamura, Y. Yamasaki, M. Kinomura et al., "Establishment and characterization of renal progenitor like cells from S3 segment of nephron in rat adult kidney," The FASEB Journal, vol. 19, no. 13, pp. 1789-1797, 2005.

[86] L. M. Curtis, S. Chen, B. Chen, A. Agarwal, C. A. Klug, and P. W. Sanders, "Contribution of intrarenal cells to cellular repair after acute kidney injury: subcapsular implantation technique," American Journal of Physiology. Renal Physiology, vol. 295, no. 1, pp. F310-F314, 2008.

[87] B. Dekel, L. Zangi, E. Shezen et al., "Isolation and characterization of nontubular sca-1+lin- multipotent stem/progenitor cells from adult mouse kidney," Journal of the American Society of Nephrology, vol. 17, no. 12, pp. 3300-3314, 2006.

[88] C. Alfarano, C. Roubeix, R. Chaaya et al., "Intraparenchymal injection of bone marrow mesenchymal stem cells reduces kidney fibrosis after ischemia-reperfusion in cyclosporineimmunosuppressed rats," Cell Transplantation, vol. 21, no. 9, pp. 2009-2019, 2012.

[89] S. J. Lee, M. O. Ryu, M. S. Seo et al., "Mesenchymal stem cells contribute to improvement of renal function in a canine kidney injury model," In Vivo, vol. 31, pp. 1115-1124, 2017.

[90] S. Takemura, T. Shimizu, M. Oka, S. Sekiya, and T. Babazono, "Transplantation of adipose-derived mesenchymal stem cell sheets directly into the kidney suppresses the progression of renal injury in a diabetic nephropathy rat model," Journal of Diabetes Investigation, vol. 11, 2019.

[91] F. Tögel, J. Isaac, Z. Hu, K. Weiss, and C. Westenfelder, "Renal SDF-1 signals mobilization and homing of CXCR4positive cells to the kidney after ischemic injury," Kidney International, vol. 67, no. 5, pp. 1772-1784, 2005.

[92] N. Liu, J. Tian, J. Cheng, and J. Zhang, "Migration of CXCR4 gene-modified bone marrow-derived mesenchymal stem cells to the acute injured kidney," Journal of Cellular Biochemistry, vol. 114, pp. 2677-2689, 2013.

[93] F. C. Brosius III, C. E. Alpers, E. P. Bottinger et al., "Mouse models of diabetic nephropathy," Journal of the American Society of Nephrology, vol. 20, no. 12, pp. 2503-2512, 2009.

[94] M. E. Hyvönen, V. Dumont, J. Tienari et al., "Early-onset diabetic E1-DN mice develop albuminuria and glomerular injury typical of diabetic nephropathy," BioMed Research International, vol. 2015, Article ID 102969, 11 pages, 2015.

[95] K. L. Hudkins, W. Pichaiwong, T. Wietecha et al., "BTBR $\mathrm{Ob} / \mathrm{Ob}$ mutant mice model progressive diabetic nephropathy," Journal of the American Society of Nephrology, vol. 21, no. 9, pp. 1533-1542, 2010.

[96] W. Pichaiwong, K. L. Hudkins, T. Wietecha et al., "Reversibility of structural and functional damage in a model of advanced diabetic nephropathy," Journal of the American Society of Nephrology, vol. 24, no. 7, pp. 1088-1102, 2013.

[97] L.-1. Kong, H. Wu, W.-p. Cui et al., "Advances in murine models of diabetic nephropathy," Journal of Diabetes Research, vol. 2013, Article ID 797548, 10 pages, 2013.

[98] R. H. Lee, M. J. Seo, R. L. Reger et al., "Multipotent stromal cells from human marrow home to and promote repair of pancreatic islets and renal glomeruli in diabetic NOD/scid mice," Proceedings of the National Academy of Sciences of the United States of America, vol. 103, no. 46, pp. 1743817443, 2006.

[99] F. E. Ezquer, M. E. Ezquer, D. B. Parrau, D. Carpio, A. J. Yañez, and P. A. Conget, "Systemic administration of multipotent mesenchymal stromal cells reverts hyperglycemia and prevents nephropathy in type 1 diabetic mice," Biology of Blood and Marrow Transplantation, vol. 14, no. 6, pp. 631640, 2008.

[100] F. Ezquer, M. Ezquer, V. Simon et al., "Endovenous administration of bone marrow-derived multipotent mesenchymal stromal cells prevents renal failure in diabetic mice," Biology of Blood and Marrow Transplantation, vol. 15, no. 11, pp. 1354-1365, 2009.

[101] Z. H. O. U. Hong, H. M. Tian, L. O. N. G. Yang et al., "Mesenchymal stem cells transplantation mildly ameliorates experimental diabetic nephropathy in rats," Chinese Medical Journal, vol. 122, pp. 2573-2579, 2009.

[102] Y. Fang, X. Tian, S. Bai et al., “Autologous transplantation of adipose-derived mesenchymal stem cells ameliorates streptozotocin-induced diabetic nephropathy in rats by inhibiting oxidative stress, pro-inflammatory cytokines and the p38 MAPK signaling pathway," International Journal of Molecular Medicine, vol. 30, no. 1, pp. 85-92, 2012.

[103] J. H. Park, J. Park, S. H. Hwang, H. Han, and H. Ha, “Delayed treatment with human umbilical cord blood-derived stem cells attenuates diabetic renal injury," Transplantation Proceedings, vol. 44, no. 4, pp. 1123-1126, 2012.

[104] J. H. Park, I. Hwang, S. H. Hwang, H. Han, and H. Ha, "Human umbilical cord blood-derived mesenchymal stem cells prevent diabetic renal injury through paracrine action," Diabetes Research and Clinical Practice, vol. 98, no. 3, pp. 465-473, 2012.

[105] S. Wang, Y. Li, J. Zhao, J. Zhang, and Y. Huang, "Mesenchymal stem cells ameliorate podocyte injury and proteinuria in a type 1 diabetic nephropathy rat model," Biology of Blood and Marrow Transplantation, vol. 19, no. 4, pp. 538-546, 2013.

[106] Y. Zhang, C. Ye, G. Wang et al., "Kidney-targeted transplantation of mesenchymal stem cells by ultrasound-targeted microbubble destruction promotes kidney repair in diabetic nephropathy rats," BioMed Research International, vol. 2013, Article ID 526367, 13 pages, 2013.

[107] S. S. Lv, G. Liu, J. P. Wang et al., "Mesenchymal stem cells transplantation ameliorates glomerular injury in streptozotocin-induced diabetic nephropathy in rats via inhibiting macrophage infiltration," International Immunopharmacology, vol. 17, no. 2, pp. 275-282, 2013.

[108] S. Lv, J. Cheng, A. Sun et al., "Mesenchymal stem cells transplantation ameliorates glomerular injury in streptozotocininduced diabetic nephropathy in rats via inhibiting oxidative stress," Diabetes Research and Clinical Practice, vol. 104, no. 1, pp. 143-154, 2014.

[109] M. A. Aziz, M. A. Wassef, H. Ahmed et al., "The role of bone marrow derived-mesenchymal stem cells in attenuation of kidney function in rats with diabetic nephropathy," Diabetology \& Metabolic Syndrome, vol. 6, no. 1, p. 34, 2014.

[110] S. Wu, L. Li, G. Wang et al., "Ultrasound-targeted stromal cell-derived factor-1-loaded microbubble destruction promotes mesenchymal stem cell homing to kidneys in diabetic 
nephropathy rats," International Journal of Nanomedicine, vol. 9, pp. 5639-5651, 2014.

[111] F. Ezquer, M. Giraud-Billoud, D. Carpio, F. Cabezas, P. Conget, and M. Ezquer, "Proregenerative microenvironment triggered by donor mesenchymal stem cells preserves renal function and structure in mice with severe diabetes mellitus," BioMed Research International, vol. 2015, Article ID 164703, 23 pages, 2015.

[112] H. Lang and C. Dai, "Effects of bone marrow mesenchymal stem cells on plasminogen activator inhibitor-1 and renal fibrosis in rats with diabetic nephropathy," Archives of Medical Research, vol. 47, no. 2, pp. 71-77, 2016.

[113] J. N. U. Yaochite, K. W. A. de Lima, C. Caliari-Oliveira et al., "Multipotent mesenchymal stromal cells from patients with newly diagnosed type 1 diabetes mellitus exhibit preserved in vitro and in vivo immunomodulatory properties," Stem Cell Research \& Therapy, vol. 7, no. 1, p. 14, 2016.

[114] A. H. Hamza, W. M. Al-Bishri, L. A. Damiati, and H. H. Ahmed, "Mesenchymal stem cells: a future experimental exploration for recession of diabetic nephropathy," Renal Failure, vol. 39, pp. 67-76, 2017.

[115] K. Nagaishi, Y. Mizue, T. Chikenji et al., "Umbilical cord extracts improve diabetic abnormalities in bone marrowderived mesenchymal stem cells and increase their therapeutic effects on diabetic nephropathy," Scientific Reports, vol. 7, no. 1, p. 8484, 2017.

[116] L. A. Rashed, S. Elattar, N. Eltablawy, H. Ashour, L. M. Mahmoud, and Y. el-Esawy, "Mesenchymal stem cells pretreated with melatonin ameliorate kidney functions in a rat model of diabetic nephropathy," Biochemistry and Cell Biology, vol. 96, no. 5, pp. 564-571, 2018.

[117] K. W. Lee, T. M. Kim, K. S. Kim et al., "Renal ischemiareperfusion injury in a diabetic monkey model and therapeutic testing of human bone marrow-derived mesenchymal stem cells," Journal of Diabetes Research, vol. 2018, Article ID 5182606, 9 pages, 2018.

[118] J. Feng, C. Lu, Q. Dai, J. Sheng, and M. Xu, "SIRT3 facilitates amniotic fluid stem cells to repair diabetic nephropathy through protecting mitochondrial homeostasis by modulation of mitophagy," Cellular Physiology and Biochemistry, vol. 46, no. 4, pp. 1508-1524, 2018.

[119] M. A. Haidara, A. S. Assiri, M. A. Youssef et al., "Differentiated mesenchymal stem cells ameliorate cardiovascular complications in diabetic rats," Cell and Tissue Research, vol. 359, no. 2, pp. 565-575, 2015.

[120] J. Ribot, G. Caliaperoumal, J. Paquet, C. Boisson-vidal, H. Petite, and F. Anagnostou, “Type 2 diabetes alters mesenchymal stem cell secretome composition and angiogenic properties," Journal of Cellular and Molecular Medicine, vol. 21, no. 2, pp. 349-363, 2017.

[121] R. Ferrer-Lorente, M. T. Bejar, M. Tous, G. Vilahur, and L. Badimon, "Systems biology approach to identify alterations in the stem cell reservoir of subcutaneous adipose tissue in a rat model of diabetes: effects on differentiation potential and function," Diabetologia, vol. 57, no. 1 , pp. 246-256, 2014.

[122] L. Shin and D. A. Peterson, "Impaired therapeutic capacity of autologous stem cells in a model of type 2 diabetes," Stem Cells Translational Medicine, vol. 1, no. 2, pp. 125-135, 2012.

[123] K. Marycz, K. Kornicka, M. Marędziak, P. Golonka, and J. Nicpoń, "Equine metabolic syndrome impairs adipose stem cells osteogenic differentiation by predominance of autoph- agy over selective mitophagy," Journal of Cellular and Molecular Medicine, vol. 20, no. 12, pp. 2384-2404, 2016.

[124] V. S. de São José, G. Monnerat, B. Guerra et al., "Bone-marrow-derived mesenchymal stromal cells (MSC) from diabetic and nondiabetic rats have similar therapeutic potentials," Arquivos Brasileiros de Cardiologia, vol. 109, no. 6, pp. 579-589, 2017.

[125] J. Tolar, A. J. Nauta, M. J. Osborn et al., "Sarcoma derived from cultured mesenchymal stem cells," Stem Cells, vol. 25, no. 2, pp. 371-379, 2007.

[126] J. O. Jeong, J. W. Han, J. M. Kim et al., "Malignant tumor formation after transplantation of short-term cultured bone marrow mesenchymal stem cells in experimental myocardial infarction and diabetic neuropathy," Circulation Research, vol. 108, no. 11, pp. 1340-1347, 2011.

[127] F. Djouad, P. Plence, C. Bony et al., "Immunosuppressive effect of mesenchymal stem cells favors tumor growth in allogeneic animals," Blood, vol. 102, no. 10, pp. 3837-3844, 2003.

[128] Z. Veceric-Haler, A. Cerar, and M. Perse, "(Mesenchymal) stem cell-based therapy in cisplatin-induced acute kidney injury animal model: risk of immunogenicity and tumorigenicity," Stem Cells International, vol. 2017, Article ID 7304643, 17 pages, 2017.

[129] E. B. Rangel, C. O. Rodrigues, and J. R. de Sa, "Micro- and macrovascular complications in diabetes mellitus: preclinical and clinical studies," Journal of Diabetes Research, vol. 2019, Article ID 2161085, 5 pages, 2019.

[130] C. Cramer, E. Freisinger, R. K. Jones et al., "Persistent high glucose concentrations alter the regenerative potential of mesenchymal stem cells," Stem Cells and Development, vol. 19, no. 12, pp. 1875-1884, 2010.

[131] V. Capilla-González, J. López-Beas, N. Escacena et al., "PDGF restores the defective phenotype of adipose-derived mesenchymal stromal cells from diabetic patients," Molecular Ther$a p y$, vol. 26, no. 11, pp. 2696-2709, 2018.

[132] Z. Kočí, K. Turnovcová, M. Dubský et al., "Characterization of human adipose tissue-derived stromal cells isolated from diabetic patient's distal limbs with critical ischemia," Cell Biochemistry and Function, vol. 32, no. 7, pp. 597-604, 2014.

[133] P. R. Moshtagh, S. H. Emami, and A. M. Sharifi, "Differentiation of human adipose-derived mesenchymal stem cell into insulin-producing cells: an in vitro study," Journal of Physiology and Biochemistry, vol. 69, no. 3, pp. 451-458, 2013.

[134] D. Marappagounder, I. Somasundaram, S. Dorairaj, and R. J. Sankaran, "Differentiation of mesenchymal stem cells derived from human bone marrow and subcutaneous adipose tissue into pancreatic islet-like clusters in vitro," Cellular \& Molecular Biology Letters, vol. 18, no. 1, pp. 75-88, 2013.

[135] L. T.-T. Dang, A. N.-T. Bui, V. M. Pham, N. K. Phan, and P. Van Pham, "Production of islet-like insulin-producing cell clusters in vitro from adipose-derived stem cells," Biomedical Research and Therapy, vol. 2, pp. 184-192, 2020.

[136] L. C. Davies, J. J. Alm, N. Heldring et al., “Type 1 diabetes mellitus donor mesenchymal stromal cells exhibit comparable potency to healthy controls in vitro," Stem Cells Translational Medicine, vol. 5, no. 11, pp. 1485-1495, 2016.

[137] K. Karina, I. Rosliana, S. Sobariah et al., "Diabetes mellitus type 2 reduces the viability, proliferation, and angiogenic marker of adipose-derived stem cells cultured in lowglucose anti-oxidant-serum supplemented medium," Biomedical Research and Therapy, vol. 6, no. 3, pp. 3073-3082, 2019. 
[138] D. Y. Li, L. K. Sorensen, B. S. Brooke et al., "Defective angiogenesis in mice lacking endoglin," Science, vol. 284, no. 5419, pp. 1534-1537, 1999.

[139] E. Fonsatti and M. Maio, "CD105+ MSC derived from adipose exhibit greater proliferation compared to CD105MSC," Journal of Translational Medicine, vol. 2, p. 18, 2004.

[140] L. H. Pham, N. B. Vu, and P. V. Pham, "The subpopulation of CD105 negative mesenchymal stem cells show strong immunomodulation capacity compared to CD105 positive mesenchymal stem cells," Biomedical Research and Therapy, vol. 6, pp. 3131-3140, 2019.

[141] J. H. Gu, J. S. Lee, D. W. Kim, E. S. Yoon, and E. S. Dhong, "Neovascular potential of adipose-derived stromal cells (ASCs) from diabetic patients," Wound Repair and Regeneration, vol. 20, no. 2, pp. 243-252, 2012.

[142] X. Deng, M. Xu, M. Shen, and J. Cheng, "Effects of type 2 diabetic serum on proliferation and osteogenic differentiation of mesenchymal stem cells," Journal of Diabetes Research, vol. 2018, Article ID 5765478, 9 pages, 2018.

[143] S. Villanueva, F. González, E. Lorca et al., "Adipose tissuederived mesenchymal stromal cells for treating chronic kidney disease: a pilot study assessing safety and clinical feasibility," Kidney Research and Clinical Practice, vol. 38, no. 2, pp. 176-185, 2019.

[144] M. N. Coutinho, A. B. Carvalho, M. A. Dalboni et al., “There is no impact of diabetes on the endothelial function of chronic kidney disease patients," Journal of Diabetes Research, vol. 2018, Article ID 7926473, 8 pages, 2018.

[145] Y. M. Azar, R. Green, C. U. Niesler, and M. van de Vyver, "Antioxidant preconditioning improves the paracrine responsiveness of bone marrow mesenchymal stem cells to diabetic wound fluid," Stem Cells and Development, vol. 27, pp. 1646-1657, 2018.

[146] C. Oses, B. Olivares, M. Ezquer et al., "Preconditioning of adipose tissue-derived mesenchymal stem cells with deferoxamine increases the production of pro-angiogenic, neuroprotective and anti-inflammatory factors: potential application in the treatment of diabetic neuropathy," PLoS One, vol. 12, article e0178011, 2017.

[147] K. Froelich, J. Mickler, G. Steusloff et al., "Chromosomal aberrations and deoxyribonucleic acid single-strand breaks in adipose-derived stem cells during long-term expansion in vitro," Cytotherapy, vol. 15, no. 7, pp. 767-781, 2013.

[148] S. Neri, P. Bourin, J.-A. Peyrafitte, L. Cattini, A. Facchini, and E. Mariani, "Human adipose stromal cells (ASC) for the regeneration of injured cartilage display genetic stability after in vitro culture expansion," PLoS One, vol. 8, no. 10, article e77895, 2013.

[149] J. Li, H. Huang, and X. Xu, "Biological characteristics and karyotiping of a new isolation method for human adipose mesenchymal stem cells in vitro," Tissue \& Cell, vol. 49, pp. 376-382, 2017.

[150] G. Q. Daley, I. Hyun, J. F. Apperley et al., "Setting global standards for stem cell research and clinical translation: the 2016 ISSCR guidelines," Stem Cell Reports, vol. 6, no. 6, pp. 787797, 2016.

[151] A. Trounson and C. McDonald, "Stem cell therapies in clinical trials: progress and challenges," Cell Stem Cell, vol. 17, no. 1, pp. 11-22, 2015.

[152] R. Abdi, P. Fiorina, C. N. Adra, M. Atkinson, and M. H. Sayegh, "Immunomodulation by mesenchymal stem cells: a potential therapeutic strategy for type 1 diabetes," Diabetes, vol. 57, no. 7, pp. 1759-1767, 2008.

[153] F. Casiraghi, G. Remuzzi, M. Abbate, and N. Perico, "Multipotent mesenchymal stromal cell therapy and risk of malignancies," Stem Cell Reviews and Reports, vol. 9, no. 1, pp. 65-79, 2013.

[154] J. S. Skyler, V. A. Fonseca, K. R. Segal, and J. Rosenstock, "Allogeneic mesenchymal precursor cells in type 2 diabetes: a randomized, placebo-controlled, dose-escalation safety and tolerability pilot study," Diabetes Care, vol. 38, pp. 1742-1749, 2015.

[155] D. K. Packham, I. R. Fraser, P. G. Kerr, and K. R. Segal, “Allogeneic mesenchymal precursor cells (MPC) in diabetic nephropathy: a randomized, placebo-controlled, dose escalation study," eBioMedicine, vol. 12, pp. 263-269, 2016.

[156] A. V. Vanikar, S. D. Dave, U. G. Thakkar, and H. L. Trivedi, "Cotransplantation of adipose tissue-derived insulinsecreting mesenchymal stem cells and hematopoietic stem cells: a novel therapy for insulin-dependent diabetes mellitus," Stem Cells International, vol. 2010, Article ID 582382, 5 pages, 2010

[157] S. D. Dave, A. V. Vanikar, H. L. Trivedi, U. G. Thakkar, S. C. Gopal, and T. Chandra, "Novel therapy for insulindependent diabetes mellitus: infusion of in vitro-generated insulin-secreting cells," Clinical and Experimental Medicine, vol. 15, no. 1, pp. 41-45, 2015.

[158] U. G. Thakkar, H. L. Trivedi, A. V. Vanikar, and S. D. Dave, "Insulin-secreting adipose-derived mesenchymal stromal cells with bone marrow-derived hematopoietic stem cells from autologous and allogenic sources for type 1 diabetes mellitus," Cytotherapy, vol. 17, pp. 940-947, 2015.

[159] J. C. Voltarelli, C. E. B. Couri, A. B. P. L. Stracieri et al., "Autologous nonmyeloablative hematopoietic stem cell transplantation in newly diagnosed type 1 diabetes mellitus," JAMA, vol. 297, no. 14, pp. 1568-1576, 2007.

[160] M. M. Lalu, L. McIntyre, C. Pugliese et al., "Safety of cell therapy with mesenchymal stromal cells (SafeCell): a systematic review and meta-analysis of clinical trials," PLoS One, vol. 7, no. 10 , article e47559, 2012.

[161] A. Mesples, N. Majeed, Y. Zhang, and X. Hu, "Early immunotherapy using autologous adult stem cells reversed the effect of anti-pancreatic islets in recently diagnosed type 1 diabetes mellitus: preliminary results," Medical Science Monitor, vol. 19, pp. 852-857, 2013.

[162] P. O. Carlsson, E. Schwarcz, O. Korsgren, and B. K. Le, "Preserved beta-cell function in type 1 diabetes by mesenchymal stromal cells," Diabetes, vol. 64, pp. 587-592, 2015.

[163] S. Bhansali, P. Dutta, V. Kumar et al., "Efficacy of autologous bone marrow-derived mesenchymal stem cell and mononuclear cell transplantation in type 2 diabetes mellitus: a randomized, placebo-controlled comparative study," Stem Cells and Development, vol. 26, no. 7, pp. 471-481, 2017.

[164] X. Gu, X. Yu, C. Zhao et al., "Efficacy and safety of autologous bone marrow mesenchymal stem cell transplantation in patients with diabetic retinopathy," Cellular Physiology and Biochemistry, vol. 49, no. 1, pp. 40-52, 2018.

[165] R. Jiang, Z. Han, G. Zhuo et al., "Transplantation of placentaderived mesenchymal stem cells in type 2 diabetes: a pilot study," Frontiers in Medicine, vol. 5, no. 1, pp. 94-100, 2011.

[166] J. Hu, X. Yu, Z. Wang et al., "Long term effects of the implantation of Wharton's jelly-derived mesenchymal stem cells 
from the umbilical cord for newly-onset type 1 diabetes mellitus,” Endocrine Journal, vol. 60, no. 3, pp. 347-357, 2013.

[167] X. Liu, P. Zheng, X. Wang et al., "A preliminary evaluation of efficacy and safety of Wharton's jelly mesenchymal stem cell transplantation in patients with type 2 diabetes mellitus," Stem Cell Research \& Therapy, vol. 5, p. 57, 2014.

[168] J. Cai, Z. Wu, X. Xu et al., "Umbilical cord mesenchymal stromal cell with autologous bone marrow cell transplantation in established type 1 diabetes: a pilot randomized controlled open-label clinical study to assess safety and impact on insulin secretion," Diabetes Care, vol. 39, pp. 149-157, 2015.

[169] J. M. Hare, J. E. Fishman, G. Gerstenblith et al., "Comparison of allogeneic vs autologous bone marrow-derived mesenchymal stem cells delivered by transendocardial injection in patients with ischemic cardiomyopathy: the POSEIDON randomized trial," JAMA, vol. 308, no. 22, pp. 2369-2379, 2012.

[170] N. Perico, F. Casiraghi, M. Introna et al., “Autologous mesenchymal stromal cells and kidney transplantation: a pilot study of safety and clinical feasibility," Clinical Journal of the American Society of Nephrology, vol. 6, no. 2, pp. 412-422, 2011.

[171] Q. Sun, Z. Huang, F. Han et al., "Allogeneic mesenchymal stem cells as induction therapy are safe and feasible in renal allografts: pilot results of a multicenter randomized controlled trial," Journal of Translational Medicine, vol. 16, p. 52, 2018.

[172] S. Ceccarelli, P. Pontecorvi, E. Anastasiadou, C. Napoli, and C. Marchese, "Immunomodulatory effect of adipose-derived stem cells: the cutting edge of clinical application," Frontiers in Cell and Developmental Biology, vol. 8, p. 236, 2020.

[173] P. Lohan, O. Treacy, M. D. Griffin, T. Ritter, and A. E. Ryan, "Anti-donor immune responses elicited by allogeneic mesenchymal stem cells and their extracellular vesicles: are we still learning?," Frontiers in Immunology, vol. 8, p. 1626, 2017.

[174] M. Kabat, I. Bobkov, S. Kumar, and M. Grumet, "Trends in mesenchymal stem cell clinical trials 2004-2018: is efficacy optimal in a narrow dose range?," Stem Cells Translational Medicine, vol. 9, pp. 17-27, 2020.

[175] A. El-Badawy and N. El-Badri, "Clinical efficacy of stem cell therapy for diabetes mellitus: a meta-analysis," PLoS One, vol. 11, no. 4, p. e0151938, 2016.

[176] X. J. Guo, F. J. Li, Y. Z. He et al., "Efficacy of autologous bone marrow mononuclear cell transplantation therapy for type 2 diabetes mellitus: an updated meta-analysis," Diabetes Ther$a p y$, vol. 10, no. 2, pp. 535-547, 2019.

[177] C. Hu and L. Li, "Preconditioning influences mesenchymal stem cell properties in vitro and in vivo," Journal of Cellular and Molecular Medicine, vol. 22, no. 3, pp. 1428-1442, 2018.

[178] Y. Feng, M. Zhu, S. Dangelmajer et al., "Hypoxia-cultured human adipose-derived mesenchymal stem cells are nononcogenic and have enhanced viability, motility, and tropism to brain cancer," Cell Death \& Disease, vol. 5, no. 12, p. e1567, 2014.

[179] J. H. Lee, Y. M. Yoon, and S. H. Lee, "Hypoxic preconditioning promotes the bioactivities of mesenchymal stem cells via the HIF-1alpha-GRP78-Akt axis," International Journal of Molecular Sciences, vol. 18, 2017.

[180] E. Szabó, R. Fajka-Boja, É. Kriston-Pál et al., “inflammatory cytokines abolishes heterogeneity of immunosuppressive function of mesenchymal stem cell population," Stem Cells and Development, vol. 24, no. 18, pp. 2171-2180, 2015.
[181] C. Tang, P. J. Russell, R. Martiniello-Wilks, J. E. Rasko, and A. Khatri, "Concise review: nanoparticles and cellular carriers-allies in cancer imaging and cellular gene therapy?," Stem Cells, vol. 28, no. 9, pp. 1686-1702, 2010.

[182] U. Kaundal, U. Bagai, and A. Rakha, "Immunomodulatory plasticity of mesenchymal stem cells: a potential key to successful solid organ transplantation," Journal of Translational Medicine, vol. 16, no. 1, p. 31, 2018.

[183] R. Namgung, K. Singha, M. K. Yu et al., "Hybrid superparamagnetic iron oxide nanoparticle-branched polyethylenimine magnetoplexes for gene transfection of vascular endothelial cells," Biomaterials, vol. 31 , no. 14, pp. 42044213, 2010.

[184] A. L. Russell, R. C. Lefavor, and A. C. Zubair, "Characterization and cost-benefit analysis of automated bioreactorexpanded mesenchymal stem cells for clinical applications," Transfusion, vol. 58, no. 10, pp. 2374-2382, 2018.

[185] M. Haack-Sørensen, M. Juhl, B. Follin et al., "Development of large-scale manufacturing of adipose-derived stromal cells for clinical applications using bioreactors and human platelet lysate," Scandinavian Journal of Clinical and Laboratory Investigation, vol. 78, no. 4, pp. 293-300, 2018.

[186] F. J. Vizoso, N. Eiro, S. Cid, J. Schneider, and R. Perez-Fernandez, "Mesenchymal stem cell secretome: toward cell-free therapeutic strategies in regenerative medicine," International Journal of Molecular Sciences, vol. 18, no. 9, p. 1852, 2017.

[187] A. Trounson and N. D. DeWitt, "Pluripotent stem cells progressing to the clinic," Nature Reviews. Molecular Cell Biology, vol. 17, no. 3, pp. 194-200, 2016. 